\title{
Laboratory study on heterogeneous decomposition of methyl chloroform on various standard aluminosilica clay minerals as a potential tropospheric sink
}

\author{
S. Kutsuna, L. Chen, K. Ohno, N. Negishi, K. Takeuchi, T. Ibusuki, K. Tokuhashi, and A. Sekiya \\ National Institute of Advanced Industrial Science and Technology (AIST), 16-1 Onogawa, Tsukuba, Ibaraki 305-8569, Japan
}

Received: 31 January 2003 - Published in Atmos. Chem. Phys. Discuss.: 1 April 2003

Revised: 18 June 2003 - Accepted: 16 July 2003 - Published: 21 July 2003

\begin{abstract}
Methyl chloroform (1,1,1-trichloroethane, $\mathrm{CH}_{3} \mathrm{CCl}_{3}$ ) was found to decompose heterogeneously on seven types of standard clay minerals (23 materials) in dry air at $313 \mathrm{~K}$ in the laboratory. All reactions proceeded through the elimination of $\mathrm{HCl} ; \mathrm{CH}_{3} \mathrm{CCl}_{3}$ was converted quantitatively to $\mathrm{CH}_{2}=\mathrm{CCl}_{2}$. The activities of the clay minerals were compared via their pseudo-first-order reaction rate constants $\left(k_{1}\right)$. A positive correlation was observed between the $k_{1}$ value and the specific surface area $(S)$ of clay minerals, where the $S$ value was determined by means of the general Brunauer-Emmett-Teller (BET) equation. The $k_{1}$ value was anti-correlated with the value of $n$, which was a parameter of the general BET equation and related to the average pore size of the clay minerals, and correlated with the water content that can be removed easily from the clay minerals. The reaction required no special pretreatment of clay minerals, such as heating at high temperatures; hence, the reaction can be expected to occur in the environment. Photoillumination by wavelengths present in the troposphere did not accelerate the decomposition of $\mathrm{CH}_{3} \mathrm{CCl}_{3}$, but it induced heterogeneous photodecomposition of $\mathrm{CH}_{2}=\mathrm{CCl}_{2}$. The temperature dependence of $k_{1}$, the adsorption equilibrium coefficient of $\mathrm{CH}_{3} \mathrm{CCl}_{3}$ and $\mathrm{CH}_{2}=\mathrm{CCl}_{2}$, and the surface reaction rate constant of $\mathrm{CH}_{3} \mathrm{CCl}_{3}$ were determined for an illite sample. The $k_{1}$ value increased with increasing temperature. The amount of $\mathrm{CH}_{3} \mathrm{CCl}_{3}$ adsorbed on the illite during the reaction was proportional to the partial pressure of $\mathrm{CH}_{3} \mathrm{CCl}_{3}$. The reaction was sensitive to relative humidity and the $k_{1}$ value decreased with increasing relative humidity. However, the reaction was found to proceed at a relative humidity of $22 \%$ at $313 \mathrm{~K}$, although the $k_{1}$ value was about one-twentieth of the value in non-humidified air. The conditions required for the reaction may be present in major desert regions of the world. A simple estimation indicates that the possible heterogeneous decomposition of $\mathrm{CH}_{3} \mathrm{CCl}_{3}$ on the ground surface in arid re-
\end{abstract}

Correspondence to: S. Kutsuna (s-kutsuna@ aist.go.jp) gions is worth taking into consideration when inferring the tropospheric lifetime of $\mathrm{CH}_{3} \mathrm{CCl}_{3}$ and global $\mathrm{OH}$ concentration from the global budget concentration of $\mathrm{CH}_{3} \mathrm{CCl}_{3}$.

\section{Introduction}

The atmospheric lifetime of methyl chloroform $(1,1,1$ trichloroethane, $\mathrm{CH}_{3} \mathrm{CCl}_{3}$ ) is required to evaluate influence of $\mathrm{CH}_{3} \mathrm{CCl}_{3}$ on the environment, for example, stratospheric ozone layer depletion (WMO, 2003) and global warming (IPCC, 2001). The lifetime has been inferred from longterm ground-based observatory data on the atmospheric concentration of $\mathrm{CH}_{3} \mathrm{CCl}_{3}$ in the ALE/GAGE/AGAGE (three sequential experiments: the Atmospheric Lifetime Experiment, the Global Atmospheric Gases Experiment, and the Advanced Global Atmospheric Gases Experiment) (Prinn et al., 1983a; Prinn et al., 1999) or in NOAA/CMDL (National Oceanic and Atmospheric Administration/Climate Monitoring and Diagnostics Laboratory) databases (Prinn et al., 1999), by model calculations (Prinn et al., 1995; Krol et al., 1998; Prinn et al., 2001) using the $\mathrm{CH}_{3} \mathrm{CCl}_{3}$ emissions data estimated (McCulloch and Midgley, 2001). In this procedure, a gas-phase reaction with $\mathrm{OH}$ is considered a main atmospheric sink of $\mathrm{CH}_{3} \mathrm{CCl}_{3}$, and photolysis and dissolution into seawater (Butler et al., 1991; Tie et al., 1992) are regarded as minor atmospheric sinks of $\mathrm{CH}_{3} \mathrm{CCl}_{3}$. The atmospheric chemistry of $\mathrm{CH}_{3} \mathrm{CCl}_{3}$ is thus related to global and hemispheric $\mathrm{OH}$ concentration. The atmospheric lifetime of $\mathrm{CH}_{3} \mathrm{CCl}_{3}$ through a reaction with $\mathrm{OH}$ inferred is scaled and used for estimating the lifetimes of chemical substances such as hydrochlorofluorocarbons and hydrofluorocarbons (Prather and Spivakovsky, 1990; Spivakovsky et al., 2000). The tropospheric lifetime of $\mathrm{CH}_{3} \mathrm{CCl}_{3}$ through a reaction with $\mathrm{OH}$ is evaluated at 6.0 years (Prinn et al., 2001).

The atmospheric concentration of $\mathrm{CH}_{3} \mathrm{CCl}_{3}$ increased in the 1980s. However, it has been decreasing dramatically 
since 1992 because of regulation under the Montreal Protocol. This decrease in atmospheric $\mathrm{CH}_{3} \mathrm{CCl}_{3}$ provides an opportunity to study the behavior of $\mathrm{OH}$ in the atmosphere (Ravishankara and Albritton, 1995; Spivakovsky et al., 2000; Montzka et al., 2000; Prinn et al., 2001). Recently, an interhemispheric difference of $\mathrm{OH}$ concentration and a decline in $\mathrm{OH}$ concentration in the last two decade have been suggested on the basis of data on the atmospheric concentration of $\mathrm{CH}_{3} \mathrm{CCl}_{3}$ (Montzka et al., 2000; Prinn et al., 2001). On the other hand, these behaviors are not supported by a 3-D model calculation or by observations of ${ }^{14} \mathrm{CO}$ (Krol et al., 1998; Manning et al., 2002). It has also been pointed out that the current estimate of global $\mathrm{OH}$ budget is more sensitive to errors in the $\mathrm{CH}_{3} \mathrm{CCl}_{3}$ emissions data because of a lower atmospheric concentration of $\mathrm{CH}_{3} \mathrm{CCl}_{3}$ (Jöckel et al., 2003). A significant underestimation of the emission rate of $\mathrm{CH}_{3} \mathrm{CCl}_{3}$ in Europe in 2000 and 2001 has been reported (Krol and Lelieveld, 2002). The use of chemical tracers other than $\mathrm{CH}_{3} \mathrm{CCl}_{3}$ to estimate the global $\mathrm{OH}$ budget has been discussed (Huang and Prinn, 2002; Jöckel et al., 2003).

In this laboratory study, we investigated an additional tropospheric sink of $\mathrm{CH}_{3} \mathrm{CCl}_{3}$, that is, heterogeneous decomposition of $\mathrm{CH}_{3} \mathrm{CCl}_{3}$ on clay minerals. If it served as a significant sink, the global $\mathrm{OH}$ concentration deduced would be influenced. It is known that $\mathrm{CH}_{3} \mathrm{CCl}_{3}$ can easily decompose heterogeneously on sands and metal surfaces under dry conditions (Rebbert and Ausloos, 1979). Kutsuna et al. (2000a) reported that dehydrochlorination of $\mathrm{CH}_{3} \mathrm{CCl}_{3}$ occurred easily on clay minerals (allophane and halloysite) at $313 \mathrm{~K}$ and indicated the possibility that the heterogeneous decomposition of $\mathrm{CH}_{3} \mathrm{CCl}_{3}$ on clay minerals at the ground surface in arid regions would serve as a potential tropospheric sink. Clay minerals are among the main components of soils and dusts. The importance of heterogeneous reactions on dust and soil has been reported by model, field, and laboratory studies on ozone, $\mathrm{SO}_{2}, \mathrm{NO}_{2}$, and so on (Dentener et al.,1996; Güsten et al., 1996; Underwood et al., 2001; Ooki and Uematsu, 2002; Hanisch and Crowley, 2003).

This paper has three main parts. In the first part, we examine the reaction of $\mathrm{CH}_{3} \mathrm{CCl}_{3}$ on nine types of standard clay minerals (25 American Petroleum Institute (API) standard clay minerals, Kerr and Kulp, 1949) with a closed-circulation reactor. We found that the decomposition of $\mathrm{CH}_{3} \mathrm{CCl}_{3}$ proceeded through $\mathrm{CH}_{3} \mathrm{CCl}_{3} \rightarrow \mathrm{CH}_{2}=\mathrm{CCl}_{2}+\mathrm{HCl}$ at $313 \mathrm{~K}$ for most of the clay minerals examined. The relationship of the reaction rate to the surface area and mineralogy of the clay minerals is discussed. In the second part, the adsorption equilibrium coefficient and the surface reaction rate constant of $\mathrm{CH}_{3} \mathrm{CCl}_{3}$ on illite and their temperature dependence are determined. Illite is a dominant clay mineral in arid regions (Claquin et al., 1999). Illite is observed in dusts from desert regions (Khalaf et al., 1985; Singer, 1988; Blanco et al., 2002; Bruintjes et al., 2002). The reaction rate increased with increasing temperature and it decreased with increasing relative humidity. Finally, on the basis of the adsorption equilibrium coefficient and the surface reaction rate obtained for the illite, the atmospheric lifetime of $\mathrm{CH}_{3} \mathrm{CCl}_{3}$ through decomposition on clay minerals is discussed. A simple estimation indicates that dry deposition due to heterogeneous decomposition on clay minerals in arid regions may serve as a tropospheric sink of $\mathrm{CH}_{3} \mathrm{CCl}_{3}$.

\section{Experimental and data analysis}

\subsection{Clay samples and measurement of their specific surface} area

The 25 kinds of standard clay materials referring to those from the American Petroleum Institute (API) (Kerr and Kulp, 1949) that were examined are listed in Table 1. Illite (API no. 35) and illite (API no. $35^{*}$ ) are different lots for the same kind of clay mineral. Four kinds of clay minerals examined in the previous study (Kutsuna et al., 2000a) are also listed for comparison in Table 1, although they are not API standard clay materials. All of the samples were purchased from Iwamoto Mineral Co., Japan. Some clay materials were grained, and all of the particles were less than $1 \mathrm{~mm}$ in diameter.

In order to determine the specific surface area of the clay samples, we measured the adsorption and desorption isotherms of $\mathrm{N}_{2}$ on the clay samples at $77 \mathrm{~K}$ using a gas sorption system (Quantachrome AUTOSORB 1). The isotherms were measured at relative pressures ranging from $10^{-3}$ to slightly under 1.0 by the static volumetric method. As described later (Sect. 3.1), the general (i.e. three-parameter) form of the Brunauer-Emmett-Teller (BET) equation was used to determine the specific surface area of the clay samples.

The clay samples examined belong to two types of aluminosilicate layer minerals. The kaolinite, halloysite, and dickite clays are 1:1 aluminosilicate layer minerals; that is, these clay minerals consist of one layer of silica $\left(\mathrm{Si}^{4+}\right)$ in tetrahedral coordination and one layer of aluminum $\left(\mathrm{Al}^{3+}\right)$ in octahedral coordination with oxygen and hydroxyl in the anion positions. The montmorillonite, metabentonite, nontronite, hectorite, and pyrophyllite clays are 2:1 aluminosilicate layer minerals; that is, these clay minerals consist of two layers of $\mathrm{Si}^{4+}$ in tetrahedral coordination and one layer of $\mathrm{Al}^{3+}$ in octahedral coordination with oxygen and hydroxyl in the anion positions. The latter layer is sandwiched by the former layers. Pyrophyllite consists of these aluminosilica layers without any exchange ions in place of $\mathrm{Al}^{3+}$ or $\mathrm{Si}^{4+}$. In montmorillonite, a magnesium ion $\left(\mathrm{Mg}^{2+}\right)$ is typically substituted for $\mathrm{Al}^{3+}$ in octahedral coordination. Substitution of $\mathrm{Al}^{3+}$ for $\mathrm{Si}^{4+}$ in tetrahedral coordination may also occur. In nontronite, ferric ion $\left(\mathrm{Fe}^{3+}\right)$ is substituted for $\mathrm{Al}^{3+}$ in octahedral coordination, while $\mathrm{Al}^{3+}$ is substituted for $\mathrm{Si}^{4+}$ in tetrahedral coordination. In hectorite, $\mathrm{Mg}^{2+}$ and a lithium ion $\left(\mathrm{Li}^{+}\right)$substitute for $\mathrm{Al}^{3+}$ in octahedral coordination. The 
Table 1. Standard clay samples examined. Their multi-plot (Eq. 11) and general (Eq. 12) BET surface area, and the reactivity against heterogeneous decomposition of $\mathrm{CH}_{3} \mathrm{CCl}_{3}$ in air at $313 \mathrm{~K}$

\begin{tabular}{|c|c|c|c|c|c|c|c|c|c|c|c|}
\hline \multirow{2}{*}{ Locality } & \multirow{2}{*}{$\begin{array}{l}\text { API } \\
\text { No. }\end{array}$} & \multicolumn{2}{|c|}{ BET plot (Eq. 11) } & \multicolumn{3}{|c|}{ g-BET plot (Eq. 12) } & \multirow{2}{*}{$\begin{array}{c}10^{5} \boldsymbol{k}_{\mathbf{1}} \\
\left(\mathrm{s}^{-1}(50 \mathrm{mg})^{-1}\right)\end{array}$} & \multirow{2}{*}{$10^{3} \mathrm{~K}$} & \multirow{2}{*}{$\begin{array}{c}10^{5} \boldsymbol{k}_{\text {clav }} \\
\left(\mathrm{s}^{-1}(50 \mathrm{mg})^{-1}\right)\end{array}$} & \multirow{2}{*}{$10^{10} \Gamma$} & \multirow{2}{*}{$N$} \\
\hline & & $\begin{array}{c}\text { area } \\
\left(\mathrm{m}^{2}\right.\end{array}$ & C & $\begin{array}{c}\text { area } \\
\left(\mathrm{m}^{2}\right.\end{array}$ & C & $n$ & & & & & \\
\hline \multirow{2}{*}{\multicolumn{2}{|c|}{$\begin{array}{l}\text { blank (no clay) } \\
\text { Kaolinite }\end{array}$}} & & & & & & $-0.01 \pm 0.08$ & $-12 \pm 3$ & & & 2 \\
\hline & & & & & & & & & & & \\
\hline Bath, S.C. & 5 & 19 & 145 & 19 & 79 & 10 & $2.7(0.1)$ & $42(15)$ & $67(25)$ & $4.6(0.2)$ & 1 \\
\hline Bath, S.C. & 7 & 26 & 170 & 27 & 86 & 10 & $2.7(0.1)$ & $15(14)$ & 190 (186) & $3.2(0.1)$ & 1 \\
\hline $\begin{array}{l}\text { Lewistown, } \\
\text { Mont. } \\
\text { Halloysite }\end{array}$ & 17 & 9 & 148 & 9 & 75 & 10 & $1.0(0.1)$ & $8(16)$ & $121(242)$ & $3.4(0.4)$ & 1 \\
\hline Bedford, Ind. & 12 & 55 & 576 & 57 & 166 & 4.3 & $12.9(0.2)$ & $213(13)$ & $74(5)$ & $8.4(0.2)$ & 1 \\
\hline $\begin{array}{l}\text { Wagon Wheel } \\
\text { Gan. Colo. }\end{array}$ & 29 & 38 & 38 & 38 & 42 & 10 & $3.7(0.1)$ & $35(14)$ & $109(42)$ & $3.0(0.1)$ & 1 \\
\hline \multicolumn{11}{|l|}{ Dickite } & \\
\hline \multicolumn{9}{|c|}{ Montmorillonite } & $-3(8)$ & $0.8(1.8)$ & 1 \\
\hline Forest, Miss. & 20 & 97 & -487 & 105 & 181 & 2.5 & $41.0 \pm 14.8$ & $171 \pm 23$ & $281 \pm 108$ & $13.8 \pm 5.0$ & 3 \\
\hline Forest, Miss. & 21 & 92 & -474 & 100 & 183 & 2.5 & $29.3(0.9)$ & 253 & $145(13)$ & $11.1(0.4)$ & 1 \\
\hline Amory Miss. & 22 & 79 & -870 & 94 & 205 & 2.9 & $16.5(0.6)$ & 300 & $72(5)$ & $7.6(0.3)$ & 1 \\
\hline Amory, Miss. & $22 \mathrm{~A}$ & 79 & -342 & 85 & 296 & 2.6 & $17.5(0.6)$ & $286(17)$ & $79(5)$ & $7.3(0.3)$ & 1 \\
\hline $\begin{array}{l}\text { Chambers, } \\
\text { Ariz. }\end{array}$ & 23 & 69 & -1635 & 74 & 171 & 2.9 & $26.6(0.8)$ & $241(20)$ & $137(12)$ & $13.6(0.5)$ & 1 \\
\hline Otay, Calif. & 24 & 32 & 314 & 34 & 105 & 4.1 & $6.5(0.3)$ & $93(18)$ & $76(15)$ & $6.4(0.3)$ & 1 \\
\hline Upton, Wyo. & 25 & 19 & 750 & 19 & 173 & 4.0 & $1.1(0.2)$ & $18(16)$ & $58(54)$ & $1.7(0.4)$ & 1 \\
\hline Clay Spur, & 26 & 25 & 166 & 26 & 83 & 10 & $1.0(0.2)$ & $10(25)$ & $107(272)$ & $1.2(0.3)$ & 1 \\
\hline $\begin{array}{l}\text { Belle Fourche, } \\
\text { S. Dak. }\end{array}$ & 27 & 21 & -1310 & 22 & 251 & 3.3 & $1.7 \pm 0.3$ & $23 \pm 10$ & $75 \pm 34$ & $2.6 \pm 0.3$ & 2 \\
\hline $\begin{array}{l}\text { Santa Rita, N. } \\
\text { Mex. }\end{array}$ & 30 & 34 & -2438 & 36 & 180 & 3.2 & $3.4(0.3)$ & $157(15)$ & $25(3)$ & $3.3(0.3)$ & 1 \\
\hline $\begin{array}{l}\text { Bayard, } \\
\text { N. Mex. }\end{array}$ & $30 \mathrm{~A}$ & 66 & -408 & 71 & 231 & 2.6 & $12.4(0.5)$ & $266(32)$ & $59(8)$ & $6.7(0.3)$ & 1 \\
\hline Cameron, Ariz. & 31 & 31 & -484 & 33 & 200 & 2.6 & $7.4(0.3)$ & $96(17)$ & $84(16)$ & $7.5(0.3)$ & 1 \\
\hline \multicolumn{12}{|c|}{ Metabentonite } \\
\hline $\begin{array}{l}\text { Tazewell, Va. } \\
\text { Nontronite }\end{array}$ & 41 & 17 & 1847 & 17 & 126 & 3.1 & $5.2(0.3)$ & $84(17)$ & $67(14)$ & $9.7(0.6)$ & 1 \\
\hline Garfield, Wash. & $33 \mathrm{~A}$ & 37 & -529 & 39 & 269 & 2.8 & $16.2(0.4)$ & $170(16)$ & $112(11)$ & $14.9(0.4)$ & 1 \\
\hline $\begin{array}{l}\text { Manito, Wash. } \\
\text { Hectorite }\end{array}$ & $33 \mathrm{~B}$ & 58 & -506 & 66 & 239 & 2.7 & $20.9(0.5)$ & $218(17)$ & $117(10)$ & $11.7(0.3)$ & 1 \\
\hline $\begin{array}{l}\text { Hector, Calif. } \\
\text { Illite }\end{array}$ & 34 & 40 & -241 & 44 & 277 & 2.3 & $48.1 \pm 23.5$ & $0 \pm 28$ & & $34 \pm 16$ & 3 \\
\hline Fithian, III. & 35 & 61 & 202 & 63 & 114 & 3.5 & $18.6 \pm 3.7$ & $149 \pm 50$ & $144 \pm 57$ & $10.3 \pm 2.1$ & 2 \\
\hline Fithian, III. & $35^{*}$ & 70 & 145 & 71 & 121 & 4.1 & $25.8 \pm 9.3$ & $206 \pm 60$ & $151 \pm 70$ & $13.4 \pm 4.9$ & 5 \\
\hline Morris, III. & 36 & 45 & 218 & 46 & 100 & 10 & $2.9 \pm 0.3$ & $60 \pm 8$ & $51 \pm 8$ & $2.0 \pm 0.2$ & 2 \\
\hline \multicolumn{12}{|c|}{ Pyrophyllite } \\
\hline Robbins, N. C. & 49 & 1 & 27 & 2 & 12 & 10 & $-0.3(0.2)$ & $-18(18)$ & $14(17)$ & $-4.6(3.2)$ & 1 \\
\hline \multicolumn{12}{|c|}{ results for clays, which are not API standard ones, in the previous work } \\
\hline Kaolinite-p & & 16 & 44 & 17 & 23 & 10 & $0.3(0.1)$ & $7(16)$ & $40(96)$ & $0.5(0.2)$ & 1 \\
\hline Halloysite-p & & 29 & 201 & 30 & 99 & 10 & $3.5(0.1)$ & $91(14)$ & $41(6)$ & $3.8(0.1)$ & 1 \\
\hline Montmorillonit & & 18 & 51 & 19 & 27 & 10 & $0.6(0.1)$ & $14(14)$ & $41(43)$ & $0.9(0.2)$ & 1 \\
\hline Allophane-p & & 235 & 13970 & 245 & 179 & 3.3 & $34.3(0.8)$ & $98(15)$ & $386(59)$ & $4.7(0.1)$ & 1 \\
\hline
\end{tabular}


above substitutions result in a negative charge on the threelayer sheet, which in turn is balanced by intersheet adsorbed cations such as calcium $\left(\mathrm{Ca}^{2+}\right)$ and sodium $\left(\mathrm{Na}^{+}\right)$ions. The intersheet $\mathrm{Ca}^{2+}$ and/or $\mathrm{Na}^{+}$interact with water molecules. It is known that the negatively charged clay surface, the exchangeable cations, aluminum at crystal edges, and transition metals in the higher valency state are related to the reactivity of clay minerals (Solomon, 1968; Mortland and Raman, 1968; Swoboda and Kunze, 1968; Theng, 1974). The formulas of the API clay materials were reported by Kerr et al. (1950).

\subsection{Experimental runs with the closed-circulation reactor}

All the experiments, except for those in Sect. 3.1 and shown in Fig. 13, were performed in a $0.85-\mathrm{dm}^{3}$ closed-circulation Pyrex reactor, which is described elsewhere in more detail (Kutsuna et al., 2000a), so only a brief summary will be given here. The reactor consists of a removable cell in which clay samples are put, a magnetic-driven glass pump, and a White-type optical cell with an optical path length of $3 \mathrm{~m}$ by which the gas mixture is analyzed using an FTIR spectrometer (JEOL Winspec 50) at a $0.5 \mathrm{~cm}^{-1}$ resolution with 50 scans. The gas mixture was circulated through the reactor with the magnetic driven glass pump $\left(0.7 \mathrm{dm}^{3} \mathrm{~min}^{-1}\right)$. It took about 3-4 min to circulate all the gas mixture through the closed-circulation reactor.

The clay samples were pretreated before each experimental run. A 50-mg sample of clay mineral particles was piled loosely on a small plate in the removable cell and exposed at atmospheric pressure to synthetic air at a rate of $0.2 \mathrm{dm}^{3} \mathrm{~min}^{-1}$ at a fixed temperature (typically $393 \mathrm{~K}$ ) for an hour. The samples were subsequently cooled to the desired reaction temperature, which was typically $313 \mathrm{~K}$. In the experiments carried out in a humidified atmosphere, the clay samples were exposed to a $0.2 \mathrm{dm}^{3} \mathrm{~min}^{-1}$ flow of humidified synthetic air of a known relative humidity for an additional $3.5 \mathrm{~h}$ at the reaction temperature.

The gas mixture of $\mathrm{CH}_{3} \mathrm{CCl}_{3}$ in air was prepared by mixing a standard gas mixture of $\mathrm{CH}_{3} \mathrm{CCl}_{3}$ in nitrogen molecules $\left(\mathrm{N}_{2}\right)$ (Takachiho-Kogyo Co., Japan) with $\mathrm{N}_{2}$ or oxygen molecules $\left(\mathrm{O}_{2}\right)$. The initial partial pressure of $\mathrm{CH}_{3} \mathrm{CCl}_{3}$ was typically set at $16 \mathrm{~Pa}$. In some experiments, the relative humidity was established by passing a part of the gas mixture through water (Ichinose-type humidifier).

The experimental procedure was as follows: the reactant gas mixture was circulated for 30 min without contact with the clay sample, and then the gas circulation path was changed so that the gas mixture flowed over the clay sample for $180 \mathrm{~min}$ without exposure to photoillumination. In most of the experiments, the gas mixture and the clay sample were then photoilluminated for $80 \mathrm{~min}$ at wavelengths longer than $300 \mathrm{~nm}$ with a 500-W xenon short-arc lamp (Ushio Co. Ltd., Japan), a mirror, and an optical filter (HOYA UV 30). The light intensity was about $6 \mathrm{~mW} \mathrm{~cm}^{-2}$ at $365 \mathrm{~nm}$ as measured with a UV sensor (USHIO UVD-365PD). The reaction temperature was controlled between 283 and $313 \mathrm{~K}( \pm 0.5 \mathrm{~K})$ by putting the removable cell in a constant-temperature water bath.

\subsection{Experimental runs with the column reactor}

A column reactor was used to examine the influence of relative humidity on the reaction in Sect. 3.3.2. The column reactor system is in principle a kind of gas chromatograph. $85 \mathrm{mg}$ of clay particles was held by small plugs of quartz wool in a Teflon tube (column reactor) with an inside diameter of $2.4 \mathrm{~mm}$. This column was put in a temperature-controlled water bath to keep the reaction temperature at $313 \mathrm{~K}$. Helium $(\mathrm{He})$ was used as a carrier gas, and it was passed through the clay sample at a rate of $5 \times 10^{-3} \mathrm{dm}^{3} \mathrm{~min}^{-1}$. The He carrier was passed through a Teflon tube $(3.2 \mathrm{~mm}$ in an outside diameter, $0.8 \mathrm{~mm}$ in thickness and about $2 \mathrm{~m}$ long) put in water at $313 \mathrm{~K}$ before introduced to the column reactor. The He carrier was expected to be humidified by water vapor passing through the Teflon wall and its relative humidity was estimated at about $1 \%$. The pressure before the column reactor was automatically controlled at atmospheric pressure by a valve (248A, MKS Co., Japan) that was located after the column reactor. The pressures before and after the column reactor were measured at 100.5 and $99.9 \mathrm{kPa}$. No pretreatment such as heating at a higher temperature was performed. In the experiment in a humidified atmosphere, the He carrier was passed through water (Ichinose-type humidifier). The relative humidity was controlled by changing the temperature of the water. A prescribed volume $\left(5 \times 10^{-3} \mathrm{dm}^{3}\right)$ of a He mixture containing xenon (Xe) by $1 \times 10^{-4}$ volume ratio or $\mathrm{CH}_{3} \mathrm{CCl}_{3}$ by $5 \times 10^{-4}$ volume ratio was injected using a multi-port valve. The shape of the peak, that is, the retention time (delay time after the injection) and the peak height, of $\mathrm{Xe}$ or $\mathrm{CH}_{3} \mathrm{CCl}_{3}$ was measured with a quadrapole mass-spectrometer. The He flow was added to the line after the column reactor to decrease the residence time in the line (dead time).

\subsection{Data analysis}

In Sect. 3.2, time course of partial pressure of $\mathrm{CH}_{3} \mathrm{CCl}_{3}$ was measured using the closed circulation reactor. Three IR spectral data were measured during $30 \mathrm{~min}$ before the $\mathrm{CH}_{3} \mathrm{CCl}_{3}$ - air mixture flowed over a clay sample. Let $P_{\text {init }}(\mathrm{Pa})$ be the mean of partial pressures measured during this period. The $\mathrm{CH}_{3} \mathrm{CCl}_{3}$ - air mixture began to flow over the clay sample at $30 \mathrm{~min}$. The sudden decrease in partial pressure of $\mathrm{CH}_{3} \mathrm{CCl}_{3}$ was observed by changing the gas circulation path. This was caused by gas adsorption on the clay sample and by changes in the circulation route that led to changes in the reactor volume. The volume change was calculated to correspond to a 23\% decrease in partial pressure. The reaction time $\left(t_{\mathrm{r}}\right.$ in 
minute) is defined as follows:

$t_{\mathrm{r}}=t-30$,

where $t$ is time in minute after the $\mathrm{CH}_{3} \mathrm{CCl}_{3}$-air mixture is introduced to the reactor without contact to the clay sample. The initial partial pressure of $\mathrm{CH}_{3} \mathrm{CCl}_{3}$ at $t_{\mathrm{r}}=0\left(P_{0 \text { init }}\right.$ in $\left.\mathrm{Pa}\right)$ was calculated as follows:

$P_{\text {init }}=0.77 \times P_{\text {init }}$.

The value of $P_{0 \text { init }}$ was used to estimate the equilibrium coefficient of $\mathrm{CH}_{3} \mathrm{CCl}_{3}$ between on the clay sample and in air as mentioned later (Eq. 4).

After contact with the clay sample, $\mathrm{CH}_{3} \mathrm{CCl}_{3}$ decreased approximately according to first-order kinetics as shown in Sect. 3.2. The decay rate was evaluated by using the quasifirst-order rate constant $k_{1}$ in $\mathrm{s}^{-1}$. That is, the $k_{1}$ value for each experiment was calculated by fitting the data at reaction time $t_{\mathrm{r}}$ (ranging from 14 to $114 \mathrm{~min}$ ) to Eq. (3). The data at $t_{\mathrm{r}}=4 \mathrm{~min}$ was not used because it did not obey firstorder kinetics. The equilibrium did not seem to be achieved at $t_{\mathrm{r}}=4 \mathrm{~min}$.

$P\left(t_{\mathrm{r}}\right)=P_{0 \text { fit }} \exp \left[-k_{1}\left(60 t_{\mathrm{r}}\right)\right]$,

where $P\left(t_{\mathrm{r}}\right)$ is the partial pressure of the $\mathrm{CH}_{3} \mathrm{CCl}_{3}$ at reaction time $t_{\mathrm{r}}$; and $P_{0 \text { fit }}$ in $\mathrm{Pa}$ is a fitting parameter. $P_{0 \text { fit }}$ means the partial pressure of $\mathrm{CH}_{3} \mathrm{CCl}_{3}$ at $t_{\mathrm{r}}=0$ that is estimated by extrapolation of Eq. (3).

The $K$ value is defined by Eq. (4), and it is given as an indication of the adsorptive activity of the clay samples for $\mathrm{CH}_{3} \mathrm{CCl}_{3}$ :

$K=\left(P_{0 \text { init }}-P_{0 \text { fit }}\right) / P_{0 \text { fit }}$.

The $K$ value is the estimate of the equilibrium mole ratio of the amount of $\mathrm{CH}_{3} \mathrm{CCl}_{3}$ adsorbed to gaseous $\mathrm{CH}_{3} \mathrm{CCl}_{3}$ at $t_{\mathrm{r}}=0$.

In Sect. 3.2, the activity of clay samples was evaluated by means of two new parameters $\left(k_{\text {clay }}\right.$ in $\mathrm{s}^{-1}$ and $\Gamma$ ) as well as $k_{1}$ and $K$. The parameter $k_{\text {clay }}$ is the first-order overall rate constant of $\mathrm{CH}_{3} \mathrm{CCl}_{3}$ adsorbed on the surface and in the pores of clay materials (Eq. 5).

$\frac{d a_{\mathrm{MC}}}{d t}=-k_{\text {clay }} a_{\mathrm{MC}}$,

where $a_{\mathrm{MC}}$ in molecules is the total amount of $\mathrm{CH}_{3} \mathrm{CCl}_{3}$ adsorbed on the surface and in the pores of the clay sample. The parameter $\Gamma$ represents reaction probability at the steady state under the experimental condition. The $k_{\text {clay }}$ and $\Gamma$ values are expressed as Eqs. (6) and (7), respectively.

$k_{\text {clay }}=\frac{1+K}{K} k_{1}$,

$\Gamma=\frac{4 V}{s v}(1+K) k_{1}$.

where $V$ is the volume of the closed-circulation reactor used $\left(8.5 \times 10^{-4} \mathrm{~m}^{3}\right) ; s$ is the surface area of the clay sample $\left(\mathrm{m}^{2}\right)$; and $v$ is the mean molecular velocity of $\mathrm{CH}_{3} \mathrm{CCl}_{3}$ $\left(\mathrm{m} \mathrm{s}^{-1}\right)$.

Equations (6) and (7) are derived as follows. Let $f_{\mathrm{MC}}$ be the mole fraction of $a_{\mathrm{MC}}$ to $\mathrm{CH}_{3} \mathrm{CCl}_{3}$ in air (outside the clay sample) under equilibrium condition. On the assumption of the steady state and a linear process, $k_{\text {clay }}$ is written as Eq. (8).

$k_{\text {clay }}=\frac{1+f_{\mathrm{MC}}}{f_{\mathrm{MC}}} k_{1}$,

The product $k_{\text {clay }} f_{\text {MC }}$ value is proportional to a flux of gaseous $\mathrm{CH}_{3} \mathrm{CCl}_{3}$ to the clay surface at the steady state. The $k_{\text {clay }}$ value and the reaction probability $(\gamma)$ satisfies Eq. (9):

$V k_{\text {clay }} f_{\mathrm{MC}}=\frac{1}{4} \gamma s v$.

Substituting Eq. (8) into Eq. (9) gives Eq. (10).

$\gamma=\frac{4 V}{s v}\left(1+f_{\mathrm{MC}}\right) k_{1}$.

In Sect. 3.2, $f_{\mathrm{MC}}$ was approximately replaced by $K$. Substituting $f_{\mathrm{MC}}=K$ into Eqs. (8) and (10) gives Eqs. (6) and (7), respectively. $\Gamma$ was used instead of $\gamma$ because $\Gamma$ was the reaction probability obtained on the above assumption.

On the other hand, in Sect. 3.3, $k_{\text {clay }}$ and $\gamma$ were calculated by Eqs. (8) and (10), respectively. That is, it was not assumed that $f_{\mathrm{MC}}=K$. The amount of $\mathrm{CH}_{3} \mathrm{CCl}_{3}$ adsorbed $\left(a_{\mathrm{MC}}\right)$ on illite (API no. $35^{*}$ ) samples was plotted against partial pressure of $\mathrm{CH}_{3} \mathrm{CCl}_{3}\left(P_{\mathrm{MC}}\right)$ at $t_{\mathrm{r}}=4-174 \mathrm{~min}$. It was found that $a_{\mathrm{MC}}$ was almost proportional to $P_{\mathrm{MC}}$ in the reaction on the illite (API no. 35*) except for the data during initial reaction periods. The $f_{\mathrm{MC}}$ value was calculated from the slope $a_{\mathrm{MC}} / P_{\mathrm{MC}}$. Temperature dependence of $k_{\text {clay }}$ and $f_{\mathrm{MC}}$ was also determined for the reaction on the illite (API no. $35^{*}$ ).

In Sect. 3.4, the lifetime of $\mathrm{CH}_{3} \mathrm{CCl}_{3}$ through the reaction on dusts or on ground surfaces was estimated. The estimation was based on the $k_{\text {clay }}$ and $f_{\mathrm{MC}}$ values determined for the illite (API no. 35*) in Sect. 3.3. The lifetime was estimated on the assumption that the equilibrium of $\mathrm{CH}_{3} \mathrm{CCl}_{3}$ between in air and on clay minerals was achieved. Since the reactions of $\mathrm{CH}_{3} \mathrm{CCl}_{3}$ on clay minerals were slow $\left(\gamma \sim 10^{-9}\right)$, this assumption was reasonable.

\section{Results and discussion}

\subsection{Surface area of the clay samples}

Figure 1 shows the adsorption/desorption isotherms of nitrogen molecules $\left(\mathrm{N}_{2}\right)$ for four API clay mineral standards at $77 \mathrm{~K}$. The $P / P_{0}$ axis represents a given relative pressure of $\mathrm{N}_{2}$, that is, the ratio of the pressure to the saturated vapor pressure. Isotherms are generally classified by their shape (Sing et al., 1985). The kaolinite isotherm (API no. 7) was Type II, and the other isotherms were Type IV. For all the minerals except for kaolinite (API no. 7), we observed hysteresis between the adsorption and the desorption isotherms. 

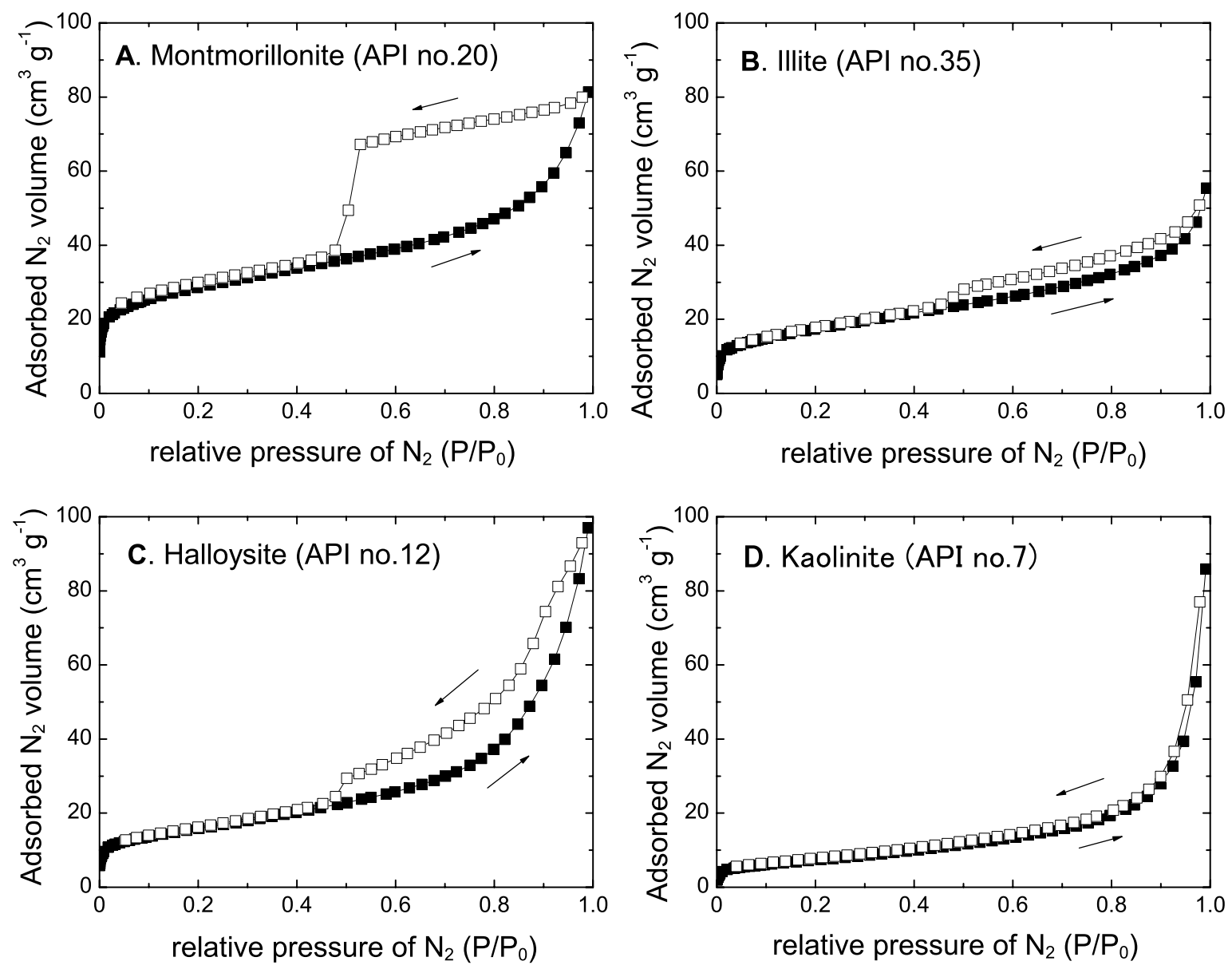

Fig. 1. Nitrogen isotherms for four types of standard clay minerals; solid square, adsorption isotherm; open square, desorption isotherm.

The types of these hysteresis loops were classified as Types $\mathrm{H} 3, \mathrm{H} 2$, and H4 for halloysite (API no. 12), montmorillonite (API no. 20), and illite (API no. 35), respectively. The hysteresis indicates that mesopores contribute to the surface area, whereas closure of the hysteresis at $P / P_{0} \approx 0.4$ suggests that there was not a significant volume of slits accessible to $\mathrm{N}_{2}$ below this width $(\sim 2.2 \mathrm{~nm})$ and that finer voids were wedge shaped. A similar hysteresis was observed for nontronite and hectorite samples, as well as for other samples of halloysite, montmorillonite and illite. For kaolinite and dickite samples, there was little hysteresis between the adsorption and desorption isotherms. For the pyrophyllite sample, a Type H4 hysteresis was observed down to $P / P_{0}=0.1$.

The surface area was initially calculated for the adsorption isotherm, in the relative pressure range $P / P_{0}=0.05-$ 0.30 , using the popular (i.e. two-parameter) BET equation (Eq. 11). The BET method is the most widely used procedure for the determination of the surface area of solid materials and involves the use of the following BET equation (Eq. 11) (Sing et al., 1985).

$W=\frac{W_{m} C\left(P / P_{0}\right)}{\left[1-\left(P / P_{0}\right)\right]\left[1+(C-1)\left(P / P_{0}\right)\right]}$, where $W$ is the weight of gas adsorbed at a given relative pressure $\left(P / P_{0}\right) ; W_{m}$ is the weight of adsorbate constituting a monolayer of surface coverage; and $P_{0}$ is the saturated vapor pressure at the temperature of the adsorbent. The term $C$, which is the BET C constant, is related to the energy of adsorption in the first adsorbed layer and consequently its value is an indication of the magnitude of the adsorbent/adsorbate interactions. The physical meaning of $\mathrm{C}$ requires that the $C$ value must be positive. The BET specific surface area and values of the BET parameter $C$ obtained are listed in Table 1. Although the $C$ value must be positive, the calculation using Eq. (11) resulted in negative $C$ values for most of the clay samples.

Therefore, the surface area was calculated by the general (i.e. three-parameter) form of the BET equation (Eq. 12) (Murray and Quirk, 1990).

$$
W=\frac{W_{m} C\left(P / P_{0}\right)\left[1-(n+1)\left(P / P_{0}\right)^{n}+n\left(P / P_{0}\right)^{n+1}\right]}{\left[1-\left(P / P_{0}\right)\right]\left[1+(C-1)\left(P / P_{0}\right)-C\left(P / P_{0}\right)^{n+1}\right]},
$$

where $n$ is the number of adsorbate layers to which multilayer formation is limited. When $n=1$, Eq. (12) is the Langmuir equation and, for large values of $n$, it assumes the 
form of Eq. (11). In practice, therefore, Eqs. (11) and (12) are virtually coincident for values of $n$ larger than $\sim 5$ and $P / P_{0}<0.3$. Equation (12) was applied to the adsorption isotherms in the relative pressure range $P / P_{0}=0.05-0.30$, by a nonlinear fitting method. The specific surface area and the parameters $C$ and $n$ obtained are listed in Table 1. This surface area will be referred to as the g-BET specific surface area $S$ in the text. In this calculation, when $n>5, n$ was fixed at a value of 10. Eq. (12) gave positive $C$ values for all clay samples. This result agrees with that reported by Murray and Quirk (1990). Hence, the g-BET surface area $S$ and the relating parameters $n$ and $C$ are used in the following discussion.

3.2 Heterogeneous decomposition on various standard clay minerals

\subsection{1 $\mathrm{HCl}$ elimination reaction}

Figure 2 depicts the infrared spectra of a $\mathrm{CH}_{3} \mathrm{CCl}_{3}$-air mixture before contact with a halloysite sample (API no. 12) at $313 \mathrm{~K}$ and at 4 and $64 \mathrm{~min}$ after contact. As the intensity of the $\mathrm{CH}_{3} \mathrm{CCl}_{3}$ peaks decreased with time, new peaks appeared at 788,869 , and $1627 \mathrm{~cm}^{-1}$. These new peaks are attributed to 1,1-dichloroethene $\left(\mathrm{CH}_{2}=\mathrm{CCl}_{2}\right)$. No decomposition products other than $\mathrm{CH}_{2}=\mathrm{CCl}_{2}$ were detected in the air mixture.

Figure 3, part $\mathrm{A}$, shows the time course of the partial pressure of $\mathrm{CH}_{3} \mathrm{CCl}_{3}\left(P_{\mathrm{MC}}\right)$ and that of $\mathrm{CH}_{2}=\mathrm{CCl}_{2}\left(P_{\mathrm{DE}}\right)$ in this reaction. At $30 \mathrm{~min}$, a $\mathrm{CH}_{3} \mathrm{CCl}_{3}$-air mixture began to flow over the halloysite material. The rapid decrease at that time was caused by gas adsorption on the halloysite and by changes in the circulation route as described in Sect. 2.4. The volume change was calculated to correspond to a $23 \%$ decrease in partial pressure. After contact with the clay sample, $\mathrm{CH}_{3} \mathrm{CCl}_{3}$ decreased approximately according to firstorder kinetics. Figure 3, part A, also shows the time course of the partial pressure of $\mathrm{CH}_{3} \mathrm{CCl}_{3}$ in a blank experimental run (with no clay samples).

Figure 3, part $\mathrm{B}$, plots the increase in $P_{\mathrm{DE}}$, which is described as $\Delta P_{\mathrm{DE}}$ hereafter, against the decrease in $P_{\mathrm{MC}}$, which is described as $-\Delta P_{\mathrm{MC}}$ hereafter, during a 180 -min reaction period. Except for the initial reaction period, the increase in $\Delta P_{\mathrm{DE}}$ was almost the same as the increase in $-\Delta P_{\mathrm{MC}}$. Hence, the reaction was judged to proceed through elimination of $\mathrm{HCl}$ (Mochida et al., 1968; Vogel et al., 1987) as follows:

$\mathrm{CH}_{3} \mathrm{CCl}_{3} \rightarrow \mathrm{CH}_{2}=\mathrm{CCl}_{2}+\mathrm{HCl}$.

Photoillumination was not required in this reaction. Hydrogen chloride $(\mathrm{HCl})$ produced could be bound to the surface of the clay samples.

At $210 \mathrm{~min}$, photoillumination $(\lambda>300 \mathrm{~nm})$ was started against $\mathrm{CH}_{3} \mathrm{CCl}_{3}-\mathrm{CH}_{2}=\mathrm{CCl}_{2}$-air mixtures in the presence of the clay material. As shown in Fig. 3, part A, photoillumination did not accelerate decomposition of $\mathrm{CH}_{3} \mathrm{CCl}_{3}$, but it induced heterogeneous photodecomposition of the
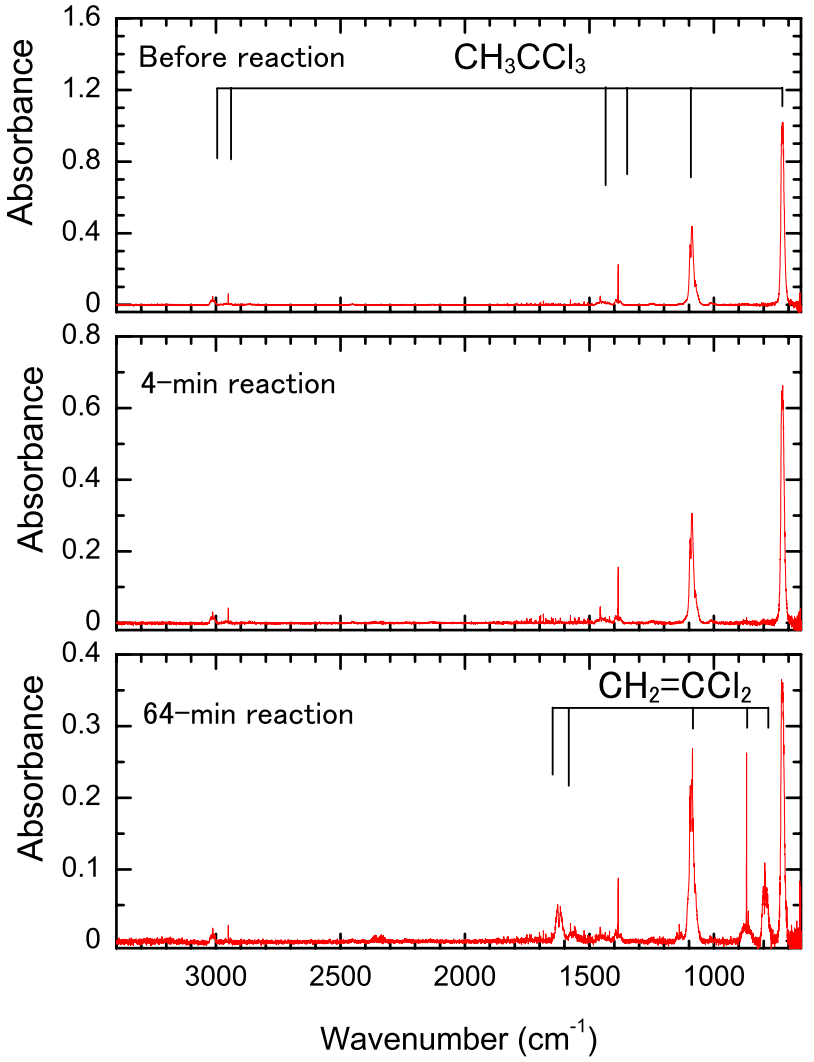

Fig. 2. IR spectra of $\mathrm{CH}_{3} \mathrm{CCl}_{3}$ and its decomposition products in the gas phase for the reaction of $\mathrm{CH}_{3} \mathrm{CCl}_{3}$ in air on halloysite (API no. 12) particles at $313 \mathrm{~K}$. (a) Before contact with the halloysite, (b) after a 4-min, and (c) after a 64-min reaction.

$\mathrm{CH}_{2}=\mathrm{CCl}_{2}$ that had been produced. $\mathrm{HCl}$ and carbon dioxide $\left(\mathrm{CO}_{2}\right)$ were detected as photodecomposition products of $\mathrm{CH}_{2}=\mathrm{CCl}_{2}$. Under photoillumination, the partial pressure of $\mathrm{CH}_{3} \mathrm{CCl}_{3}$ seems to be almost constant. This effect was also observed for the reactions on other clay minerals. It will be discussed later (Sect. 3.2.3). In the text, the reactions under photoillumination are described only in Sect. 3.2.3; otherwise, "reaction" means the reaction without photoillumination.

In a similar way, decomposition of $\mathrm{CH}_{3} \mathrm{CCl}_{3}$ and formation of $\mathrm{CH}_{2}=\mathrm{CCl}_{2}$ were confirmed in dry air at $313 \mathrm{~K}$ for most the API standard clay minerals examined. Since $\mathrm{CH}_{3} \mathrm{CCl}_{3}$ decreased exponentially with time, the decay rate and the adsorptive activity were evaluated as described in Sect. 2.4. The $k_{1}$ and $K$ values obtained are listed in Table 1 . The $k_{\text {clay }}$ and $\Gamma$ values calcualted by Eqs. (6) and (7), respectively, are also listed in Table 1 . The values in parentheses represent the errors deduced by the non-linear regression. The errors in this text indicate $\pm \sigma$. The error of $K$ is calculated not only from the error of $P_{0 \text { fit }}$ but also the error of the factor 0.77 in Eq. (2) that is estimated to be 0.01. N in Table 1 indicates the number of experimental runs. When 

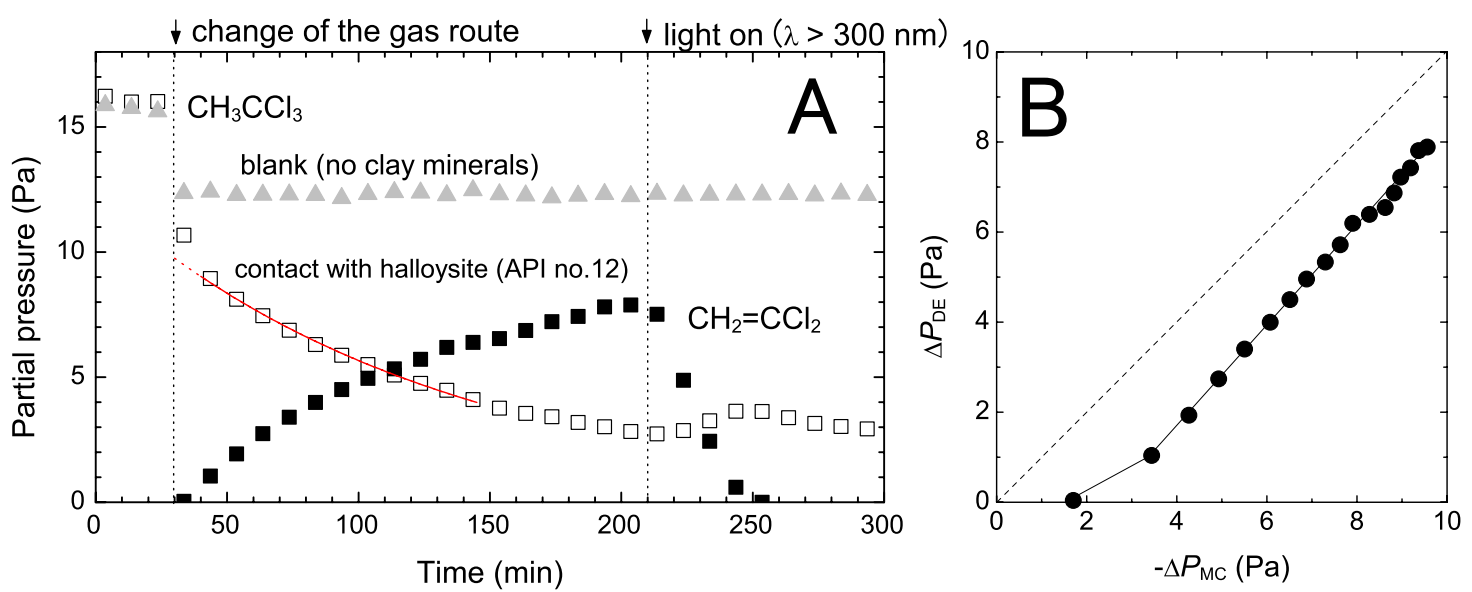

Fig. 3. Changes in $\mathrm{CH}_{3} \mathrm{CCl}_{3}$ and newly formed $\mathrm{CH}_{2}=\mathrm{CCl}_{2}$ for the reaction shown in Fig. 2. (A) Time course of $\mathrm{CH}_{3} \mathrm{CCl}_{3}$ (open symbol) and newly formed $\mathrm{CH}_{2}=\mathrm{CCl}_{2}$ (solid symbol) partial pressures. Solid red line is a fit by first-order kinetics. Upward-pointing triangle symbols indicate time course of $\mathrm{CH}_{3} \mathrm{CCl}_{3}$ in a blank experimental run (with no clay minerals). (B) The decrease in $\mathrm{CH}_{3} \mathrm{CCl}_{3}$ partial pressure $\left(-\Delta P_{\mathrm{MC}}\right)$ versus the increase in $\mathrm{CH}_{2}=\mathrm{CCl}_{2}$ partial pressure $\left(\Delta P_{\mathrm{DE}}\right)$ during a 180 -min reaction without photoillumination.

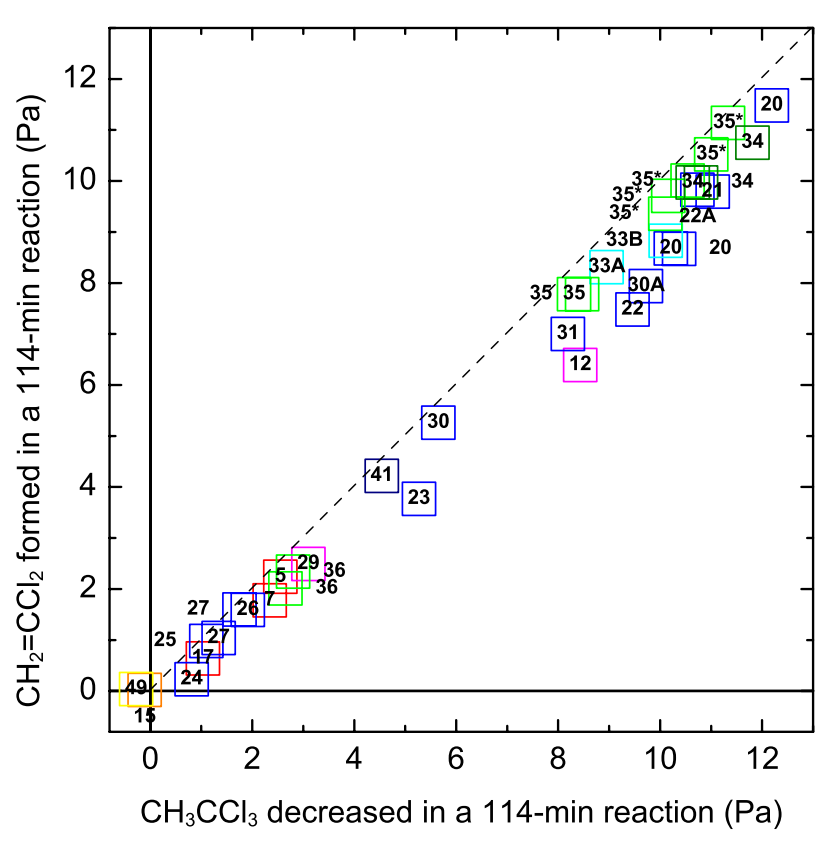

Fig. 4. The decrease in $\mathrm{CH}_{3} \mathrm{CCl}_{3}$ partial pressure $\left(-\Delta P_{\mathrm{MC}}\right)$ versus the increase in $\mathrm{CH}_{2}=\mathrm{CCl}_{2}$ partial pressure $\left(\Delta P_{\mathrm{DE}}\right)$ for 114-min reactions on various API standard clay minerals at $313 \mathrm{~K}$. The label indicates the API number of the clay minerals. Clay minerals of the same type are represented by the same color.

several experiments were carried out $(N>1)$, the mean and the standard deviation of the mean are listed in Table 1. Except for the dickite (API no. 15) and the pyrophyllite (API no. 49) samples, the decomposition of $\mathrm{CH}_{3} \mathrm{CCl}_{3}$ on clay minerals in dry air at $313 \mathrm{~K}$ was confirmed by the positive value of $k_{1}$.
Figure 4 plots $\Delta P_{\mathrm{DE}}$ against $-\Delta P_{\mathrm{MC}}$ for $114 \mathrm{~min}$ of reaction time for all clay samples examined. The two values are almost the same for each mineral, which implies that the decomposition on the clay minerals examined occurred through the $\mathrm{HCl}$ elimination reaction shown in Eq. (13). $\mathrm{HCl}$ was not observed in the gas phase except for the reaction on the hectorite sample (API no. 34). Thus, $\mathrm{HCl}$ seems to be bound to the surface of most the clay minerals. The result for the hectorite sample (API no. 34) will be discussed later (in Sect. 3.2.4).

3.2.2 Relation of $k_{1}, K, k_{\text {clay }}$ and $\Gamma$ with the surface area and mineralogy of the clay minerals

The order of the $k_{1}$ values for the different minerals typed was as follows: hectorite, nontronite $>$ halloysite, metabentonite $>$ kaolinite $\gg$ dickite, pyrophyllite. For the montmorillonite samples, the $k_{1}$ value varied from $1 \times 10^{-5}$ to $41 \times 10^{-5} \mathrm{~s}^{-1}$ for $50 \mathrm{mg}$ of sample. In a previous study (Kutsuna et al., 2000a), the montmorillonite sample examined showed a small value of $k_{1}$ (montmorillonite-p in Table 1), but in this study several of the montmorillonite samples exhibited much larger $k_{1}$ values. As for the illite samples examined, the $k_{1}$ value of one material (no. 35 or $35^{*}$ ) was ten times that of the other material (no. 36).

Figure 5, part A, plots the $k_{1}$ value against the g-BET specific surface area $(S)$ for each clay sample. The $k_{1}$ value correlated positively with the $S$ value. The positive correlation between the $k_{1}$ and $S$ values is in contrast to the relation observed in the heterogeneous decomposition of some hydrofluoroethers on similar clay materials (Kutsuna et al., 2002; however, in that study, the surface area was calculated by Eq. 11). The slope $k_{1} / s$ is estimated to be $5.7 \times 10^{-5} \mathrm{~s}^{-1} \mathrm{~m}^{-2}$ with a correlation coefficient $(R)$ of 0.72 , 

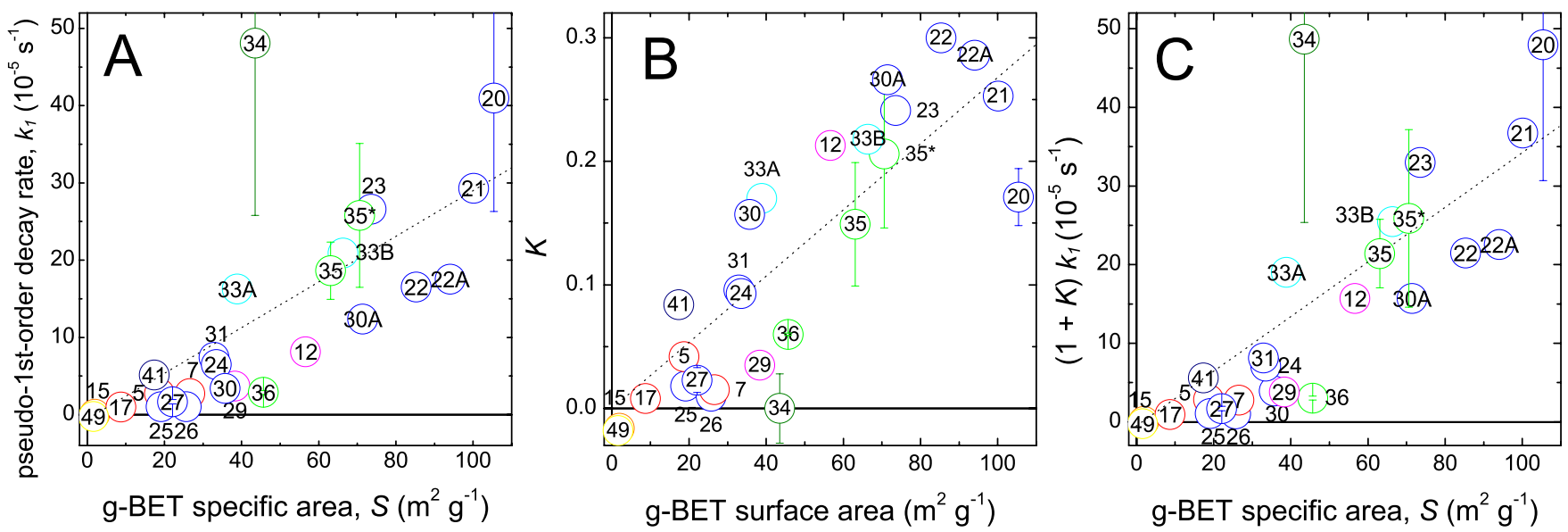

Fig. 5. (A) Pseudo-first-order rate constant $k_{1}$, (B) equilibrium ratio estimated for the adsorption $K$, and $(\mathbf{C})(1+K) k_{1}$ in reactions on various API standard clay minerals at $313 \mathrm{~K}$ versus specific surface area $S$ of each clay mineral deduced by Eq. (12). The label indicates the API number of the clay minerals. Clay minerals of the same type are represented by the same color.

where $s$ is the surface area of $50 \mathrm{mg}$ of the clay material, that is, $s=0.05 \times S$. Figure 5, part B, shows the $K$ value versus the g-BET surface area. The adsorption was almost proportional to the g-BET surface area. The slope $K / s$ is estimated to be $5.4 \times 10^{-2} \mathrm{~m}^{-2}(R=0.85)$. Figure 5 , part $\mathrm{C}$, shows the product $k_{1}(1+K)$ versus the g-BET surface area. As described in Sect. 2.4 (Eq. 7), the slope $k_{1}(1+K) / s$ is proportional to the reaction probability $\Gamma$. The slope $k_{1}(1+K) / s$ is calculated to be $(6.8 \pm 0.7) \times 10^{-5} \mathrm{~s}^{-1}(\mathrm{R}=0.78)$. By Eq. (7), $\Gamma$ is calculated to be $(1.0 \pm 0.1) \times 10^{-9}$ when $223 \mathrm{~m} \mathrm{~s}^{-1}$ is given for mean molecular velocity of $\mathrm{CH}_{3} \mathrm{CCl}_{3}$ at $313 \mathrm{~K}$.

Although the $k_{1}$ and $k_{\text {clay }}$ values are roughly proportional to the $s$ value, the $\Gamma$ values vary by one orders of magnitude. For example, the hectorite sample (API no. 34) has the largest value of $\Gamma$. Among the 12 montmorillonite materials, the $\Gamma$ values vary from $1.2 \times 10^{-10}$ to $1.4 \times 10^{-9}$. For one illite sample (API no. 35 or $35^{*}$ ), $\Gamma$ was about five times larger than for the other illite sample (API no. 36).

In general, not all of the internal surface area of porous solids always participates in the reaction (Keyser et al., 1991). The clay materials examined have mesopores and micropores, as mentioned in Sect. 3.1. Therefore, it is necessary to check whether the BET surface area corresponds to all of the surface area accessible to $\mathrm{CH}_{3} \mathrm{CCl}_{3}$. The ratio of the surface area participating in the reaction is indicated by the effectiveness factor $\eta$. As for an irreversible first-order reaction with a reaction rate constant of $k_{1 \mathrm{e}}\left(\mathrm{s}^{-1}\right)$, the $\eta$ value of flat materials with narrow cylindrical pores and of porous spherical materials can be calculated by Eq. (14) or (14'), respectively, as follows (Levenspiel, 1999):

$\eta=\frac{\tanh \phi}{\phi}$ for flat materials with narrow cylindrical pores;

$\eta=\frac{3}{\phi}\left(\frac{1}{\tanh \phi}-\frac{1}{\phi}\right)$,

for porous spherical materials,

where $\phi$ is Tiele's modulus, which is calculated by Eqs. (15) or $\left(15^{\prime}\right)$ :

$\phi=L\left(k_{1 \mathrm{e}} / D_{\mathrm{MC}}\right)^{1 / 2}$,

for flat materials with narrow cylindrical pores;

$\phi=R_{\mathrm{p}}\left(k_{1 \mathrm{e}} / D_{\mathrm{MC}}\right)^{1 / 2}$,

for porous spherical materials,

where $L$ is length of cylindrical pores; $D_{\mathrm{MC}}$ is the effective diffusion coefficient of $\mathrm{CH}_{3} \mathrm{CCl}_{3}$ in the pores; and $R_{\mathrm{p}}$ is the radius of the pores. In both types of porous materials, the $\eta$ value becomes almost unity when $\phi<1$. In the reactions examined, $L$ and $R_{\mathrm{p}}$ can be less than $10^{-3} \mathrm{~m}$. The order of the $k_{1 \mathrm{e}}$ value can be estimated from the $k_{1}$ values as $<10^{-3} \mathrm{~s}^{-1}$. The $D_{\mathrm{MC}}$ value depends on the structure of the pores and is difficult to estimate, but it should not be $<10^{-9} \mathrm{~m}^{2} \mathrm{~s}^{-1}$. Hence, $\eta$ can be evaluated as $<1$, and the $\phi$ value is expected to be about unity. Thus, the variability of $\Gamma$ is not due to the different $\eta$ values of the clay materials.

Figure 6, part A, plots the $\Gamma$ value against the g-BET parameter $n$. The $\Gamma$ values tend to be large for clay materials with small $n$. For example, the hectorite sample (API no. 34), which exhibits the largest $\Gamma$ value, has the smallest $n$ value. There is a distinct difference in $n$ between the two illite materials (API nos. 35 or $35^{*}$ and 36 ). The reason for this relation between $\Gamma$ and $n$ is not clear. A possible explanation is as follows. As described in Sect. 3.1, a small value of $n$ means that there are many narrow voids accessible to $\mathrm{N}_{2}$ (for example, cumulative voids about $0.4 \sim 1.4 \mathrm{~nm}$ in diameter for $n=2$ ). 

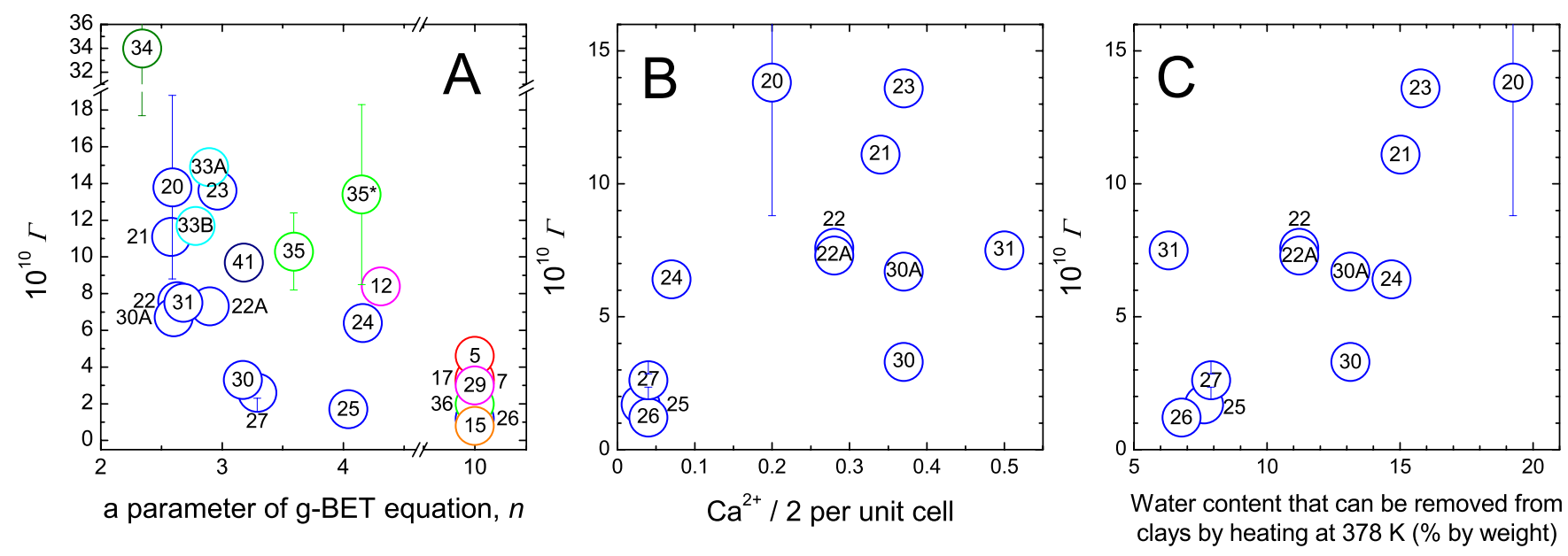

Fig. 6. (A) The $\Gamma$ value in reactions on various API standard clay minerals at $313 \mathrm{~K}$ versus a parameter of the general BET equation, $n$. (B) The $\Gamma$ value versus interlayer $\mathrm{Ca}^{2+}$ in a unit cell of the clay minerals (Kerr et al., 1950). (C) The $\Gamma$ value versus amount of $\mathrm{H}_{2} \mathrm{O}$ released from clay minerals by heating at $378 \mathrm{~K}$ in per cent by weight (Kerr et al., 1950).

These voids are formed by connections between clay crystals via their faces and/or edges. The anti-correlation of $n$ and $\Gamma$ suggests that such narrow voids may serve as reaction sites. These voids may accelerate the reaction under special circumstances such as in intense electric fields (Aochi and Farmer, 1995).

For the montmorillonite samples, the relation between $\Gamma$ and $n$ is ambiguous. For example, materials with similar small values of $\Gamma$ (API nos. 25, 26, and 27) have values of $n$ from 3.3 to 10 . The correlation of the $\Gamma$ value with the mineralogy of the montmorillonite materials was checked on the basis of their reported chemical analyses (Kerr et al., 1950). The chemical formulas of the clay samples (API nos. 22A and 30A) were assumed to be, respectively, the same as the clay samples (API nos. 22 and 30). No correlation of the $\Gamma$ value with the charge at the clay surface nor with the substituted metal in tetrahedral and octahedral coordination was found. The $\Gamma$ value seemed to correlate with the concentration of interlayer $\mathrm{Ca}^{2+}$ and with the water content of the clay minerals examined. Figure 6 , parts B and $\mathrm{C}$, plots the $\Gamma$ value against the concentration of the interlayer $\mathrm{Ca}^{2+}$ and the water content, respectively. The water content shown in Fig. 6, part $\mathrm{C}$, presents the amount of the water that the clay could release at $<378 \mathrm{~K}$. The Ca-montmorillonite materials tended to exhibit larger $\Gamma$ values than the Na-montmorillonite materials with the exception of two montmorillonite (API nos. 24 and 30). The positive correlation between the $\Gamma$ value and the amount of water loosely bound to the clay indicates that sites formed by removal of water can serve as active sites for the decomposition of $\mathrm{CH}_{3} \mathrm{CCl}_{3}$. It is known that solid acid sites can serve as active sites for the decomposition of $\mathrm{CH}_{3} \mathrm{CCl}_{3}$ (Mochida et al., 1968). Solid acid sites seem to be present under dry conditions (Zielke et al., 1989). The adsorption/desorption behavior of water seems to be a key to the reactivity of clay minerals against the decomposition of $\mathrm{CH}_{3} \mathrm{CCl}_{3}$, as mentioned later in Sects. 3.2.3 and 3.3.2.

\subsubsection{Effects of pretreatment, reaction temperature, and photoillumination}

In this study, the clay samples were dried at $393 \mathrm{~K}$ for $1 \mathrm{~h}$ in air flow before the reaction. This commonly used procedure for drying clay minerals is said to not destroy their structure. On the other hand, it is well known that the activity of clay minerals, for example, their acidity, depends on the water content of the surface (Zielke et al., 1989). Hence, the effect of the pretreatment temperature was examined for three clay materials (API nos. 20, 34, and 35*). Figure 7 plots the $k_{1}$ values measured for the reaction on each clay material against the pretreatment temperature. The $k_{1}$ values seem to decrease with decreasing pretreatment temperature. However, the difference was less than the measurement error for $k_{1}$. The decomposition of $\mathrm{CH}_{3} \mathrm{CCl}_{3}$ was confirmed at pretreatment temperatures down to $323 \mathrm{~K}$. The purpose of the pretreatment is the removal of some of the water from the clay minerals. In general, clay minerals lose water at temperatures a little higher than ambient temperature. Reaction conditions similar to the pretreatment in this study can be found in natural environments, particularly in hot and dry regions such as the Sahara Desert.

The $k_{1}$ value increased with increasing reaction temperature. Figure 8, parts A and B, shows a semi-logarithm plot of the typical time course of $P_{\mathrm{MC}}$ in typical reactions on hectorite (API no. 34) and illite (API no. 35*), respectively, at $283-313 \mathrm{~K}$. The decay rate for each reaction at each different temperature was evaluated by the quasi-first-order rate constant $k_{1}$, as described in Sect. 2.4. Some data determined during the initial reaction period did not obey first-order kinetics, 


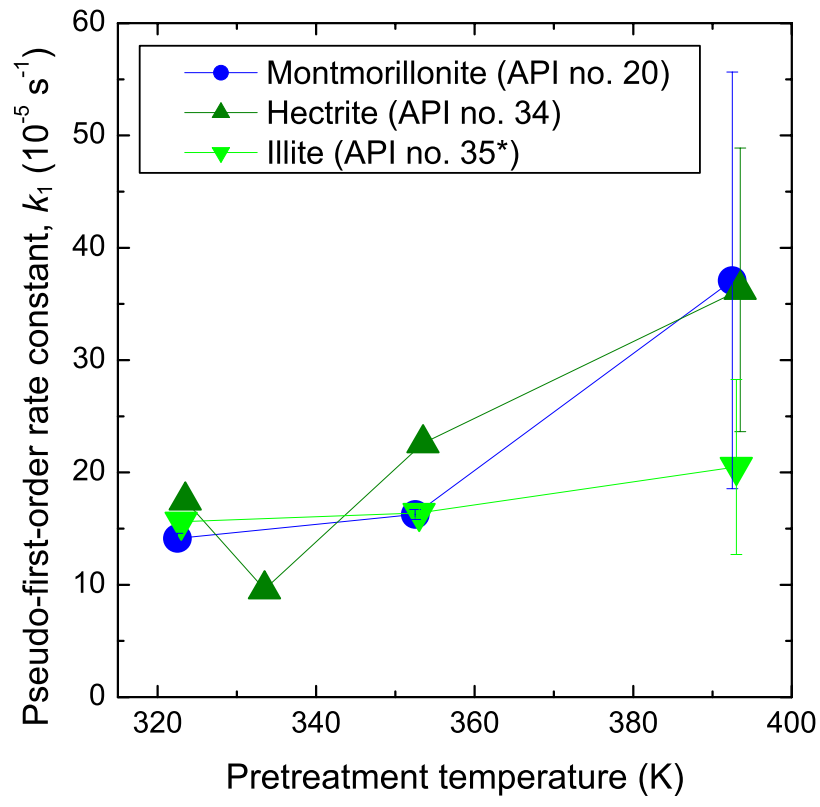

Fig. 7. The pseudo-first-order reaction rate in reactions on clay minerals at $313 \mathrm{~K}$ versus the pretreatment temperature of clay minerals. The pretreatment temperature means the temperature at which montmorillonite (API no. 20), hectorite (API no. 34), or illite (API no. $\left.35^{*}\right)$ was heated before the reaction.

probably because the adsorption equilibrium was not yet established. Accordingly, the data was fitted for the reaction times between 14 and $114 \mathrm{~min}$ for the reaction at $313 \mathrm{~K}$, and for those between 74 and $174 \mathrm{~min}$ for the reactions at 298 and 283 K. Figure 8 , part C, plots the $k_{1}$ values obtained against the inverse of the reaction temperature. For the reaction at $313 \mathrm{~K}$ on hectorite (API no.34) and the reactions at 283$313 \mathrm{~K}$ on illite (API no. $35^{*}$ ), several experiments were run. Figure 8, part C, plots the mean of the $k_{1}$ values for those reactions at each temperature. The error bars show the standard deviation of the mean at each temperature for illite (API no. 35*), while the error bars for hectorite (API no. 34) were set at the ratio of error to the mean at $313 \mathrm{~K}(46 \%)$. The apparent activation energies $(\Delta E)$ of the reactions on hectorite (API no. 34) and illite (API no. 35*) were calculated as (71 \pm $24)$ and $(37 \pm 21) \mathrm{kJ} \mathrm{mol}^{-1}$, respectively, by the weightednonlinear regression of the data using the Arrhenius equation, $k_{1}=A_{\mathrm{r}} \exp [(-\Delta E / R) / T]$. These apparent activation energies are smaller by about 150 and $180 \mathrm{~kJ} \mathrm{~mol}^{-1}$, respectively, than that for the homogeneous gas-phase thermal decomposition of $\mathrm{CH}_{3} \mathrm{CCl}_{3}\left(220 \mathrm{~kJ} \mathrm{~mol}^{-1}\right)$ (Weissman and Benson, 1984). In contrast, they are larger than the activation energy (12.9 $\mathrm{kJ} \mathrm{mol}^{-1}$ ) (DeMore et al., 1997) for the gaseous reaction with $\mathrm{OH}$, which is a main tropospheric process for the removal of $\mathrm{CH}_{3} \mathrm{CCl}_{3}$. The relative importance of the reaction on clay minerals to the gaseous reaction with $\mathrm{OH}$ thus increases with increasing temperature.
$\mathrm{CH}_{3} \mathrm{CCl}_{3}$ did not decompose by photoillumination $(\lambda>$ $300 \mathrm{~nm}$ ), as shown in Fig. 3, part A, for any clay materials. In contrast, $\mathrm{CH}_{2}=\mathrm{CCl}_{2}$, which had been produced, decomposed through a heterogeneous photoreaction on the clay minerals except for some montmollironite (API nos. 25 and 27). For the dickite (API no. 15) and the pyrophyllite (API no. 49), photodecomposition of $\mathrm{CH}_{2}=\mathrm{CCl}_{2}$ was not examined in this study, because $\mathrm{CH}_{2}=\mathrm{CCl}_{2}$ had not been produced from $\mathrm{CH}_{3} \mathrm{CCl}_{3}$ on these clay minerals. The photodecomposition of $\mathrm{CH}_{2}=\mathrm{CCl}_{2}$ on the API standard clay minerals seems to proceed via two schemes: heterogeneous photodecomposition of $\mathrm{CH}_{2}=\mathrm{CCl}_{2}$ and the reaction of $\mathrm{CH}_{2}=\mathrm{CCl}_{2}$ with $\mathrm{Cl}$ atoms that are released from $\mathrm{CH}_{2}=\mathrm{CCl}_{2}$ in a similar way as observed for halloysite-p and kaolinite-p in the previous study (Kutsuna et al., 2000b). $\mathrm{CO}_{2}$ were detected as a gaseous photodecomposition product of $\mathrm{CH}_{2}=\mathrm{CCl}_{2}$. When the photodecomposition rate was large, $\mathrm{HCl}$ was observed.

As described in Sect. 3.2.1 (Fig. 3, part A), the decay rate of $\mathrm{CH}_{3} \mathrm{CCl}_{3}$ was decreased under photoillumination, and this was the case for most clay minerals. This behavior can be ascribed in part to gradually decreasing activity of clay minerals during a 180-min reaction before photoillumination. But, compared with effect of this inactivation, the decrease in decay rate of $\mathrm{CH}_{3} \mathrm{CCl}_{3}$ was large in most the reactions. For a case of the reaction on halloysite (API no. 12) as shown in Fig. 3, when photoillumination was started, $\mathrm{CH}_{3} \mathrm{CCl}_{3}$ increased due to desorption from the clay surface. The desorption decreased the decay rate of $\mathrm{CH}_{3} \mathrm{CCl}_{3}$ under photoillumination. $\mathrm{CH}_{3} \mathrm{CCl}_{3}$ seems to be released by increasing temperature of the clay surface under photoillumination. The desorption can also be explained by accumulation of photodecompositon products such as $\mathrm{HCl}$ on the clay surface. This explanation is supported by the fact that $\mathrm{CH}_{3} \mathrm{CCl}_{3}$ decreased under photoillumination after disappearance of $\mathrm{CH}_{2}=\mathrm{CCl}_{2}$ (Fig. 3). The inhibiting effect of the photodecomposition products of $\mathrm{CH}_{2}=\mathrm{CCl}_{2}$ can be expected to be less significant in the environment because diffusion of newly formed $\mathrm{CH}_{2}=\mathrm{CCl}_{2}$ to the atmosphere decreases $\mathrm{CH}_{2}=\mathrm{CCl}_{2}$ over clay minerals to much lower concentrations in the environment than in this study.

\subsubsection{Reaction on hectorite}

The hectorite material (API no. 34) had the largest $\Gamma$ value. In the reaction on hectorite, $\mathrm{HCl}$ was observed as a gaseous product. The ready release of $\mathrm{HCl}$ from the clay surface is probably the reason that the $\Gamma$ value is so large. After $\mathrm{HCl}$ increased in the air mixture, it decreased by being adsorbed onto the hectorite. As shown in Fig. 8, the apparent activation energy for the reaction on hectorite (API no. 34) was larger than that for the reaction on illite (API no. $\left.35^{*}\right)$. The large value of $\Gamma$ for hectorite (API no. 34) does not result from the lower activation energy of the reaction on hectorite. Hectorite (API no. 34) has some remarkable features in comparison with the other clay minerals 

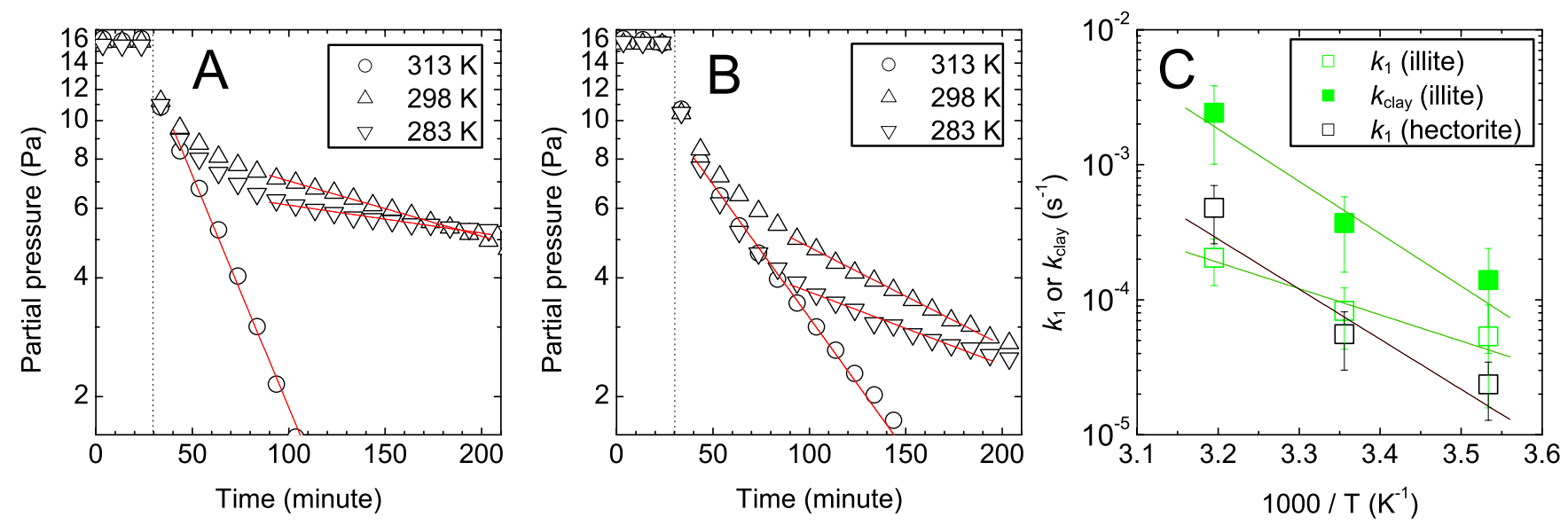

Fig. 8. (A) Semi-log plot of the time course of $\mathrm{CH}_{3} \mathrm{CCl}_{3}$ partial pressures for the reactions on hectorite (API no. 34) and (B) on illite (API no. $\left.35^{*}\right)$ at $283-313 \mathrm{~K}$. (C) The $k_{1}$ values averaged for the reaction on hectorite (API no. 34) and the $k_{1}$ and $k_{\text {clay }}$ values averaged for the reaction on illite (API no. $35^{*}$ ) versus the inverse of reaction temperatures; open square, $k_{1}$; solid square, $k_{\text {clay }}$.

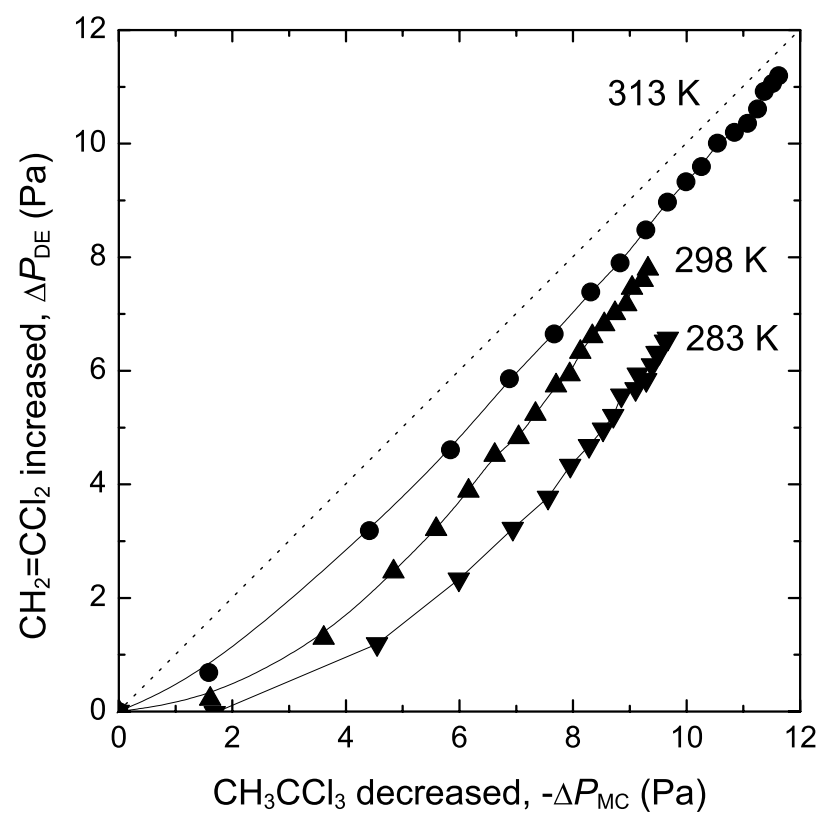

Fig. 9. The decrease in $\mathrm{CH}_{3} \mathrm{CCl}_{3}$ partial pressure $\left(-\Delta P_{\mathrm{MC}}\right)$ versus the increase in $\mathrm{CH}_{2}=\mathrm{CCl}_{2}$ partial pressure $\left(\triangle P_{\mathrm{DE}}\right)$ during reactions on illite (API no. $35^{*}$ ) materials at 283,298 , and $313 \mathrm{~K}$.

examined: the presence of $\mathrm{Li}$ and $\mathrm{F}$ atoms, the trioctahedral sheet, and the presence of micropores. These features may be related to the ready release of $\mathrm{HCl}$ into the air and the large number of reaction sites, which may result in the large $\Gamma$ value.

\subsection{Reaction on illite}

3.3.1 Temperature dependence of the adsorption and surface reaction

The temperature dependence of the adsorption was considered separately from that of the surface reaction of $\mathrm{CH}_{3} \mathrm{CCl}_{3}$ for the reactions on illite (API no. $35^{*}$ ). Figure 9 plots $\Delta P_{\mathrm{DE}}$ against $-\triangle P_{\mathrm{MC}}$ for each reaction on illite (API no. $35^{*}$ ) shown in Fig. 8, part A. The discrepancy between $\Delta P_{\mathrm{DE}}$ and $-\Delta P_{\mathrm{MC}}$ increased as the temperature decreased from 313 to $283 \mathrm{~K}$. The discrepancy observed during the initial reaction period and that for the reactions at lower temperatures can be explained by the presence of $\mathrm{CH}_{3} \mathrm{CCl}_{3}$ or $\mathrm{CH}_{2}=\mathrm{CCl}_{2}$ or both, which did not react, adsorbed onto the clay surface. This explanation is supported by the fact that the formation rate of $\mathrm{CH}_{2}=\mathrm{CCl}_{2}$ and the rate of decrease of $\mathrm{CH}_{3} \mathrm{CCl}_{3}$ were almost the same after the initial reaction periods.

In order to evaluate the amount of $\mathrm{CH}_{2}=\mathrm{CCl}_{2}$ adsorbed ( $a_{\mathrm{DE}}$ in molecules) in these reactions, the adsorption of $\mathrm{CH}_{2}=\mathrm{CCl}_{2}$ was measured at temperatures of $283-313 \mathrm{~K}$ using the closed-circulation reactor. The results are shown in Fig. 10. The data were analyzed by using the Langmuir adsorption Eq. (16):

$a_{\mathrm{DE}}=\frac{m S q^{\mathrm{DE}} K_{\mathrm{p}}^{\mathrm{DE}} P_{\mathrm{DE}}}{1+K_{\mathrm{p}}^{\mathrm{DE}} P_{\mathrm{DE}}}$,

where $m$ is the mass of the clay mineral in $\mathrm{g} ; S$ is the specific surface area of the clay minerals in $\mathrm{m}^{2} \mathrm{~g}^{-1} ; q^{\mathrm{DE}}$ is a temperature-independent parameter in $\mathrm{m}^{-2}$; and $K_{\mathrm{P}}^{\mathrm{DE}}$ is an equilibrium constant in $\mathrm{Pa}^{-1}$. The parameters $q^{\mathrm{DE}}$ and $K_{\mathrm{P}}^{\mathrm{DE}}$ are obtained by a nonlinear regression of all the data at different temperatures with the same value of $q^{\mathrm{DE}}$. The 

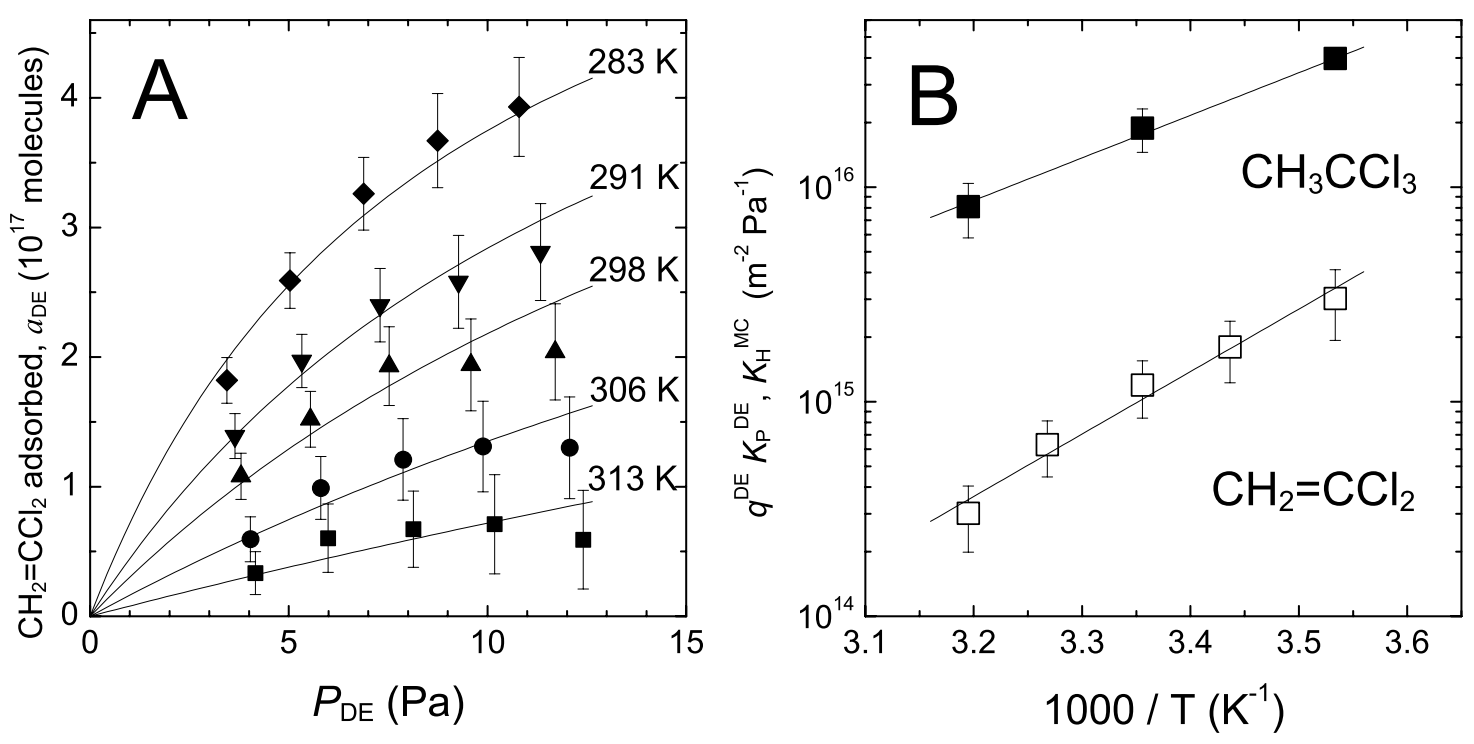

Fig. 10. Adsorption on illite (API no. 35*). (A) Isotherms of $\mathrm{CH}_{2}=\mathrm{CCl}_{2}$ in air at $283-313 \mathrm{~K}$. (B) The temperature dependence of the adsorption parameters for $\mathrm{CH}_{2}=\mathrm{CCl}_{2}$ (open symbols) and $\mathrm{CH}_{3} \mathrm{CCl}_{3}$ (solid symbols).

regression gave $q^{\mathrm{DE}}=(2.0 \pm 0.4) \times 10^{17}\left(\mathrm{~m}^{-2}\right)$ and $K_{\mathrm{P}}^{\mathrm{DE}}$ $=1.5 \pm 0.5,3.2 \pm 0.9,6.0 \pm 1.8,9.0 \pm 2.9$, and $15.1 \pm 5.5\left(10^{-3}\right.$ $\mathrm{Pa})$ at $313,306,298,291$, and $283 \mathrm{~K}$, respectively. The $a_{\mathrm{DE}}$ values calculated from these values are shown by solid curves in Fig. 10, part A. The product $q^{\mathrm{DE}} K_{\mathrm{P}}^{\mathrm{DE}}$ is plotted against the inverse of temperature in Fig. 10, part B. The $K_{\mathrm{P}}^{\mathrm{DE}}$ value obeys Eq. (17).

$K_{\mathrm{P}}^{\mathrm{DE}}\left(T_{2}\right)=K_{\mathrm{P}}^{\mathrm{DE}}\left(T_{1}\right) \exp \left[\left(\Delta E_{\text {ads }} / R\right)\left(T_{1}^{-1}-T_{2}^{-1}\right)\right]$,

where $K_{\mathrm{P}}^{\mathrm{DE}}\left(T_{1}\right)$ and $K_{\mathrm{P}}^{\mathrm{DE}}\left(T_{2}\right)$ are the adsorption constants at temperatures $T_{1}$ and $T_{2}$ in $\mathrm{K}$, respectively; $\Delta E_{\text {ads }}$ is the heat of adsorption $\left(\mathrm{J} \mathrm{mol}^{-1}\right)$; and $R$ is the universal gas constant $\left(8.31 \mathrm{~J} \mathrm{~mol}^{-1} \mathrm{~K}^{-1}\right)$. The value of $\Delta E_{\text {ads }}$ was calculated as $-(56 \pm 10) \mathrm{kJ} \mathrm{mol}^{-1}$ by fitting the data to Eq. (17) using the weighted-nonlinear regression with the weight of $\sigma_{e}^{-2}$, where $\sigma_{e}$ was the error bar size of each data.

The amount of $\mathrm{CH}_{3} \mathrm{CCl}_{3}$ adsorbed onto the clay surface ( $a_{\mathrm{MC}}$ in molecules) was calculated as follows:

$a_{\mathrm{MC}}=2.07 \times 10^{17}\left(-\Delta P_{M C}-\Delta P_{D E}\right)-a_{D E}$,

where the factor $2.07 \times 10^{17}$ in molecules $\mathrm{Pa}^{-1}$ is a result of the units used in Eq. (18). In all reactions, $a_{\mathrm{MC}}$ was much larger than $a_{\mathrm{DE}}$. As mentioned in Sect. 2.4, the uncertainty in $\Delta P_{\mathrm{MC}}$ due to the pressure drop is estimated at about 0.16 $\mathrm{Pa}$ in gaseous $\mathrm{CH}_{3} \mathrm{CCl}_{3}$, which corresponds to $3.3 \times 10^{16}$ molecules in $a_{\mathrm{MC}}$. On the other hand, errors of $a_{\mathrm{DE}}$ are estimated at $<4 \times 10^{15}$ molecules when $P_{\mathrm{DE}}<10 \mathrm{~Pa}$ at $313 \mathrm{~K}$. Hence, error of $a_{\mathrm{MC}}$ is estimated at about $3 \times 10^{16}$. Errors of $a_{\mathrm{DE}}$ are estimated at $1.4 \times 10^{16}$ and $3.5 \times 10^{16}$ molecules at 298 and $283 \mathrm{~K}$, respectively, when $P_{\mathrm{DE}}=10 \mathrm{~Pa}$. Hence, errors of $a_{\mathrm{MC}}$ are estimated at (4-5) $\times 10^{16}$ molecules at these temperatures.
Table 2. The values of $k_{1}$ and $K_{\mathrm{H}}^{\mathrm{MC}}$ measured, and the $k_{\text {clay values }}$ calculated for reactions of $\mathrm{CH}_{3} \mathrm{CCl}_{3}$ in air on illite (API no. $35^{*}$ ) at $283-313 \mathrm{~K}$. The data for all the experimental runs and the mean of them at each temperature were listed

\begin{tabular}{cccc}
\hline & & & \\
$T(\mathrm{~K})$ & $k_{1}\left(10^{-5} \mathrm{~s}^{-1}\right)$ & $\left(10^{16} \mathrm{~m}^{-2} \mathrm{~Pa}^{-1}\right)$ & $k_{\text {clay }}\left(10^{-4} \mathrm{~s}^{-1}\right)$ \\
\hline 313 & 11.6 & 1.13 & 7.1 \\
& 24.0 & 0.82 & 19.5 \\
& 25.9 & 0.90 & 19.6 \\
& 35.8 & 0.52 & 44.9 \\
mean & 31.9 & 0.69 & 30.4 \\
\hline 298 & $25.8 \pm 9.3$ & $0.81 \pm 0.23$ & $24.3 \pm 14.2$ \\
& 3.9 & 2.37 & 1.4 \\
mean & $8.3 \pm 4.0$ & $1.68 \pm 0.43$ & 3.4 \\
\hline 283 & 1.2 & 4.21 & 4.2 \\
& 8.5 & 3.93 & 0.3 \\
& 6.5 & 3.75 & 2.1 \\
mean & $5.4 \pm 3.8$ & $3.97 \pm 0.23$ & $1.4 \pm 1.0$ \\
\hline
\end{tabular}

Figure 11 plots $a_{\mathrm{MC}}$ versus $P_{\mathrm{MC}}$ for all experimental runs at $313 \mathrm{~K}$ (part A), $298 \mathrm{~K}$ (part B), and $283 \mathrm{~K}$ (part C). Except for the data from the initial reaction period, colored in gray, each data set can be fitted by a straight line intersecting the origin. A Henry's law type equation (Eq. 19) thus applied under the reaction conditions examined.

$a_{\mathrm{MC}}=m S K_{\mathrm{H}}^{\mathrm{MC}} P_{\mathrm{MC}}$, 


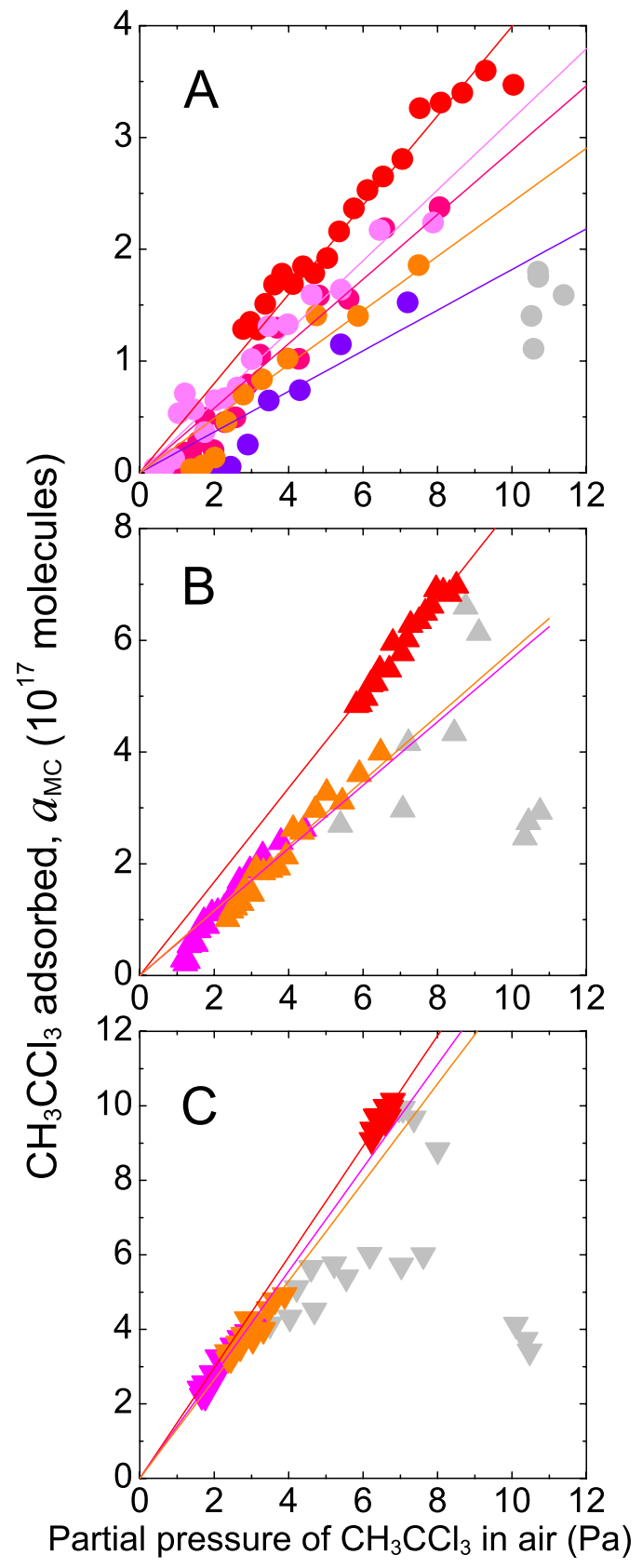

Fig. 11. The amount of $\mathrm{CH}_{3} \mathrm{CCl}_{3}$ adsorbed on illite (API no. $\left.35^{*}\right)$ versus the partial pressure of $\mathrm{CH}_{3} \mathrm{CCl}_{3}$ in the reactions of $\mathrm{CH}_{3} \mathrm{CCl}_{3}$-air mixtures on illite (API no. $35^{*}$ ) materials at (A) $313 \mathrm{~K}$, (B) $298 \mathrm{~K}$, and (C) $283 \mathrm{~K}$. Different colors in each part of the figure indicate the data for different experimental runs. Solid lines are fits by Eq. (19) in the text. Gray symbols are data used during the initial reaction periods, but they were not fitted.

where $m$ is the mass of the clay mineral in $\mathrm{g} ; S$ is the specific surface area of the clay mineral in $\mathrm{m}^{2} \mathrm{~g}^{-1}$; and $K_{\mathrm{H}}^{\mathrm{MC}}$ is an adsorption constant of the Henry's law-type equation in $\mathrm{m}^{-2} \mathrm{~Pa}^{-1}$. The $K_{\mathrm{H}}^{\mathrm{MC}}$ values derived by regressing the data in Fig. 11 are listed in Table 2 along with the $k_{1}$ value obtained as described before. The $K_{\mathrm{H}}^{\mathrm{MC}}$ are also plotted in Fig. 10, part B. The stronger adsorption of $\mathrm{CH}_{3} \mathrm{CCl}_{3}$ compared with that of $\mathrm{CH}_{2}=\mathrm{CCl}_{2}$ is indicated by $K_{\mathrm{H}}^{\mathrm{MC}}>$ $q^{\mathrm{DE}} K_{\mathrm{P}}^{\mathrm{DE}}$. The $K_{\mathrm{H}}^{\mathrm{MC}}(T)$ at temperature $T$ in $\mathrm{K}$ was written as Eq. (20) by weighted-nonlinearly regressing the data with the weight of $\sigma_{\mathrm{e}}^{-2}$, where $\sigma_{\mathrm{e}}$ was the error bar size of each data, by using the equation of $K_{\mathrm{H}}^{\mathrm{MC}}(T)=B \exp \left[\Delta E_{\text {ads }} /(R T)\right]$, where $\Delta E_{\text {ads }}$ is the heat of adsorption $\left(\mathrm{J} \mathrm{mol}^{-1}\right) ; B$ is a parameter in $\mathrm{m}^{-2} \mathrm{~Pa}^{-1}$; and $R$ is the universal gas constant $\left(8.31 \mathrm{~J} \mathrm{~mol}^{-1} \mathrm{~K}^{-1}\right)$.

$K_{\mathrm{H}}^{\mathrm{MC}}(T)=3.87 \times 10^{9} \exp (4570 / T)$.

The heat of adsorption $\Delta E_{\text {ads }}$ of $\mathrm{CH}_{3} \mathrm{CCl}_{3}$ is calculated to be $-(38 \pm 6) \mathrm{kJ} \mathrm{mol}^{-1}$.

In order to consider the temperature-dependence of adsorption and surface reaction separately, we simplified the reaction scheme as follows:

$$
\begin{aligned}
& \mathrm{CH}_{3} \mathrm{CCl}_{3}(\mathrm{~g}) \rightleftarrows \mathrm{CH}_{3} \mathrm{CCl}_{3} \text { (pore), } \quad k_{21} \\
& \mathrm{CH}_{3} \mathrm{CCl}_{3} \text { (pore) } \rightleftarrows \mathrm{CH}_{3} \mathrm{CCl}_{3}(\mathrm{ad}), \quad K_{22} \\
& \mathrm{CH}_{3} \mathrm{CCl}_{3}(\mathrm{ad}) \rightarrow \mathrm{CH}_{2}=\mathrm{CCl}_{2}(\mathrm{ad})+\mathrm{HCl}(\mathrm{ad}), \quad k_{23} \\
& \mathrm{CH}_{2}=\mathrm{CCl}_{2}(\mathrm{ad}) \rightleftarrows \mathrm{CH}_{2}=\mathrm{CCl}_{2}(\mathrm{~g}),
\end{aligned}
$$

where $k_{21}$ is a constant originating from diffusion of $\mathrm{CH}_{3} \mathrm{CCl}_{3}$ in pores; $K_{22}$ is the adsorption equilibrium coefficient of $\mathrm{CH}_{3} \mathrm{CCl}_{3}$ in pores; $k_{23}$ is the first-order surface reaction rate constant in pores; $\mathrm{CH}_{3} \mathrm{CCl}_{3}$ (g) and $\mathrm{CH}_{3} \mathrm{CCl}_{3}$ (pore) are gaseous $\mathrm{CH}_{3} \mathrm{CCl}_{3}$ outside and in pores, respectively; $\mathrm{CH}_{3} \mathrm{CCl}_{3}(\mathrm{ad})$ is $\mathrm{CH}_{3} \mathrm{CCl}_{3}$ adsorbed on the surfaces in pores; and $\mathrm{CH}_{2}=\mathrm{CCl}_{2}(\mathrm{ad})$ and $\mathrm{HCl}(\mathrm{ad})$ are $\mathrm{CH}_{2}=\mathrm{CCl}_{2}$ and $\mathrm{HCl}$, respectively, adsorbed on the surfaces in pores. To simplify an explanation, only reactions on the surface in pores are considered. This simplification is reasonable because the surface area in pores is much larger than the surface area outside pores of most clay materials examined.

Since the $k_{23}$ value is much smaller than the adsorption rate and the desorption rate, equilibrium of $\mathrm{CH}_{3} \mathrm{CCl}_{3}$ between in air and on the surface can be expected to be determined by $K_{22}$. The steady state flux of $\mathrm{CH}_{3} \mathrm{CCl}_{3}$ to pores by diffusion $\left(F_{\text {diff }}\right)$ is represented by Eq. $(25)$.

$F_{\text {diff }}=k_{21}\left(P_{\mathrm{MC}(\mathrm{g})}-P_{\mathrm{MC}(\text { pore })}\right)$,

where $P_{\mathrm{MC}(\mathrm{g})}$ and $P_{\mathrm{MC} \text { (pore) }}$ are partial pressures of gasphase $\mathrm{CH}_{3} \mathrm{CCl}_{3}$ (outside clay samples) and equilibrium partial pressure of $\mathrm{CH}_{3} \mathrm{CCl}_{3}$ adsorbed in pores. It is assumed that $\mathrm{CH}_{3} \mathrm{CCl}_{3}$ in pores is removed according to first-order kinetics by reactions on the inner surface of pores of clay minerals by Eq. (26).

$\frac{d P_{\mathrm{MC}(\text { pore })}}{d t}=-k_{\mathrm{d}} P_{\mathrm{MC}(\text { pore })}$, 
where $k_{\mathrm{d}}=k_{23} K_{22}$. Since $F_{\text {diff }}=-d P_{\mathrm{MC}(\text { pore })} / d t=-k_{\text {clay }}$ $f_{\mathrm{MC}} P_{\mathrm{MC}(\mathrm{g})}$ at steady state, where $k_{\text {clay }}$ and $f_{\mathrm{MC}}$ are defined in Sect. 2.4, Eq. (27) is obtained:

$\left(k_{\text {clay }} f_{\mathrm{MC}}\right)^{-1}=k_{21}^{-1}+k_{d}^{-1}$.

Substituting Eq. (8) to Eq. (27) gives Eq. (28):

$\left(1+f_{\mathrm{MC}}\right)^{-1} k_{1}^{-1}=k_{21}^{-1}+k_{d}^{-1}$.

The $k_{21}$ value is estimated to be $>10^{-3} \mathrm{~s}^{-1}$ at $313 \mathrm{~K}$, because $\mathrm{CH}_{3} \mathrm{CCl}_{3}$ decayed according to first-order kinetics after 14 min-reaction period. The $k_{21}$ value is expected to decrease with decreasing temperature and thus it took longer time at 298 and $283 \mathrm{~K}$ till the adsorption equilibrium was achieved. The $k_{21}$ values at these temperatures are estimated to be $>2 \times 10^{-4} \mathrm{~s}^{-1}$. In addition, the formation rate of $\mathrm{CH}_{2}=\mathrm{CCl}_{2}$ is measured to be almost same as the decay rate of $\mathrm{CH}_{3} \mathrm{CCl}_{3}$ except for the initial period after changing the gas-circulating route. These facts indicate that $k_{1} \ll k_{21}$ and that $\left(1+f_{\mathrm{MC}}\right) k_{1}$ is nearly equal to $k_{\mathrm{d}}$. Physical meaning of $k_{1}$ is represented by Eq. (28) on the assumption of the steady state and linear processes as shown in schemes (21)(24). In these schemes, under quasi-equilibrium conditions, the equilibrium mole ratio $f_{M C}$, which is defined in Sect. 2.4, is represented as follows:

$f_{\mathrm{MC}}=1.71 \times 10^{-17} K_{\mathrm{H}}^{\mathrm{MC}}$,

where the factor $1.71 \times 10^{-17}$ in $\mathrm{m}^{2} \mathrm{~Pa}$ is a result of the units used in Eq. (29). Substituting Eq. (29) to Eq. (8) gives Eq. (30):

$k_{\text {clay }}=\left(1+5.85 \times 10^{16} K_{\mathrm{H}}^{\mathrm{MC}-1}\right) k_{1}$.

The $k_{\text {clay }}$ value can be calculated by using Eq. (30) with the measured $k_{1}$ and $K_{\mathrm{H}}^{\mathrm{MC}}$ values. The $k_{\text {clay }}$ values are listed in Table 2 and are plotted in Fig. 8, part C. By weightednonlinearly regressing the data in Fig. 8, part C, by using the Arrhenius equation, the $k_{\text {clay }}(T)$ value in $\mathrm{s}^{-1}$ at temperature $T$ in K was expressed by Eq. (31) and the activation energy of the surface reaction $\Delta E_{\mathrm{r}}$ obtained is $(74 \pm 31) \mathrm{kJ} \mathrm{mol}^{-1}$ :

$k_{\text {clay }}(T)=4.78 \times 10^{9} \exp (-8930 / T)$.

\subsubsection{Effects of relative humidity}

The dry surface of clay minerals seems to play an important role in the decomposition of $\mathrm{CH}_{3} \mathrm{CCl}_{3}$, as mentioned in Sect. 3.2.3. We also found previously that the decomposition rate of $\mathrm{CH}_{3} \mathrm{CCl}_{3}$ on clay minerals (halloysite and allophane) decreased with increasing relative humidity (Kutsuna et al., 2000a). Figure 12 shows the $k_{1}$ value and the amount of $\mathrm{CH}_{2}=\mathrm{CCl}_{2}$ produced in a 114-min reaction at different relative humidities. Both the $k_{1}$ value and the amount of $\mathrm{CH}_{2}=\mathrm{CCl}_{2}$ decreased with increasing relative humidity. At $43 \%$ relative humidity, the formation of $\mathrm{CH}_{2}=\mathrm{CCl}_{2}$ was not detected and the $k_{1}$ value was about one-fiftieth of the

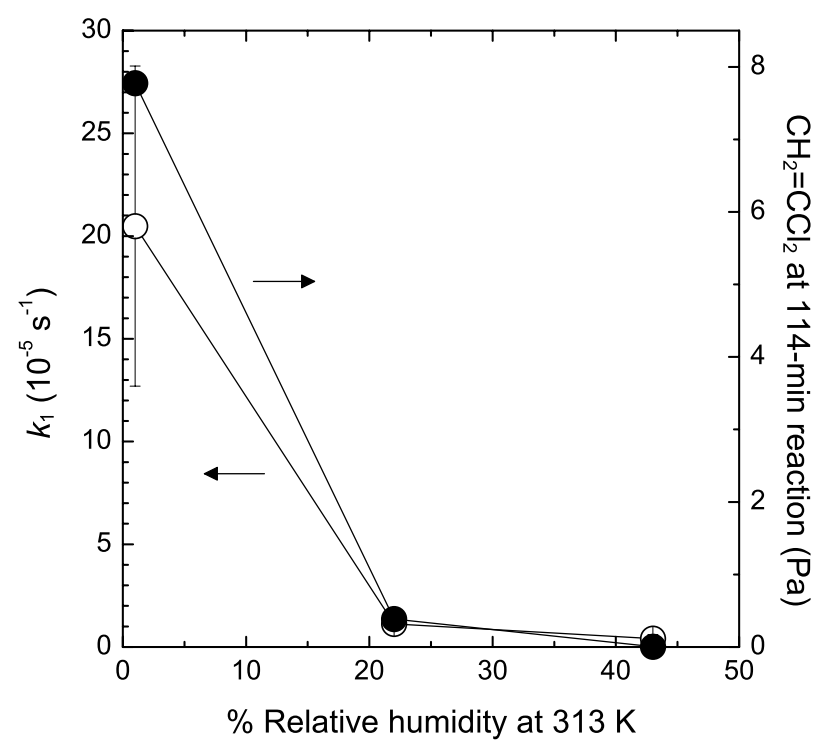

Fig. 12. The effects of the relative humidity on a reaction of a $\mathrm{CH}_{3} \mathrm{CCl}_{3}$-air mixture on illite (API no. $35^{*}$ ) materials at $313 \mathrm{~K}$. Open symbols represent the pseudo-first-order rate constant; solid symbols represent the amount of $\mathrm{CH}_{2}=\mathrm{CCl}_{2}$ produced in a 114-min reaction.

value in dry air. At $22 \%$ relative humidity, $\mathrm{CH}_{2}=\mathrm{CCl}_{2}$ formation and the $k_{1}$ value were about 18 and 20 times smaller, respectively, than in dry air. The decomposition of $\mathrm{CH}_{3} \mathrm{CCl}_{3}$ proceeded even at $22 \%$ relative humidity, however, at $313 \mathrm{~K}$.

The effect of relative humidity was examined by means of a column reactor experiment as mentioned in Sect. 2.3. Figure 13, part A, shows the xenon peak (Xe) after a Xe$\mathrm{He}$ mixture and a non-humidified He carrier-gas flow were passed through the column, which contained $85 \mathrm{mg}$ of illite material (API No. 35*), at 313 K. Figure 13, parts B-D, shows the $\mathrm{CH}_{3} \mathrm{CCl}_{3}$ peaks after a $\mathrm{CH}_{3} \mathrm{CCl}_{3}-\mathrm{He}$ mixture and $\mathrm{He}$ carrier-gas flow with controlled relative humidity were passed through the column at $313 \mathrm{~K}$. Xe was used as a reference because little is adsorbed onto clay minerals. The corrected retention time $r t(\mathrm{MC})$ is defined as Eq. (32):

$r t(\mathrm{MC})=t(\mathrm{MC})-t(\mathrm{Xe})$,

where $t(\mathrm{Xe})$ and $t(\mathrm{MC})$ are the respective retention times of the $\mathrm{Xe}$ and $\mathrm{CH}_{3} \mathrm{CCl}_{3}$ peaks. The value of $r t(\mathrm{MC})$ is approximately proportional to the adsorption equilibrium coefficient of $\mathrm{CH}_{3} \mathrm{CCl}_{3}$ on the illite sample (API no. 35*). The adsorption of $\mathrm{CH}_{3} \mathrm{CCl}_{3}$ on the clay minerals at $43 \%$ and $17 \%$ relative humidity decreased by about 34 and 16 times, respectively, compared with adsorption in a non-humidified atmosphere (about $1 \%$ relative humidity). The column experiment indicates that water content on the surface decreases the adsorption of $\mathrm{CH}_{3} \mathrm{CCl}_{3}$ on the clay surface, which seems to be related to the decrease in the reaction rate due to relative humidity. In addition, it confirms that $\mathrm{CH}_{3} \mathrm{CCl}_{3}$ can be adsorbed on the clay surface at $17 \%$ relative humidity. 


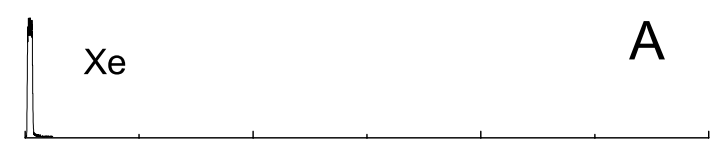

$43 \% \mathrm{RH}(313 \mathrm{~K})$
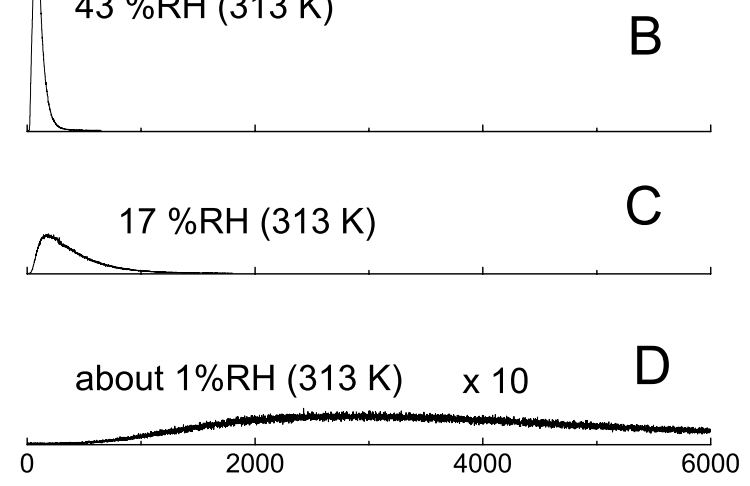

Time after injecting a sample with a valve (s)

Fig. 13. The results of the column experiment for illite (no. $\left.35^{*}\right)$ in dry or humidified He flow at $313 \mathrm{~K}$. (A) The experiment of a Xe-He mixture in dry He flow (about $1 \% \mathrm{RH}$ ). (B)-(D) The experiments of a $\mathrm{CH}_{3} \mathrm{CCl}_{3}-\mathrm{He}$ mixture in (B) $43 \% \mathrm{RH}$, (C) $17 \% \mathrm{RH}$, and (D) dry He flow.

3.4 Environmental implications of the reaction of $\mathrm{CH}_{3} \mathrm{CCl}_{3}$ on clay minerals

\subsubsection{Estimated lifetime through decomposition on clays in} airborne dusts

The values obtained for $k_{\text {clay }}$ and $K_{\mathrm{H}}^{\mathrm{MC}}$ in Sect. 3.3.1 indicate that mass-transport processes such as a gas diffusion process cannot be the rate-limiting step for removal by airborne dust. In this case, the removal rate of $\mathrm{CH}_{3} \mathrm{CCl}_{3}\left(\tau_{\text {dust }}^{\text {local }-1}\right.$ in year $^{-1}$ ) is determined as follows. First, the distribution factor of $\mathrm{CH}_{3} \mathrm{CCl}_{3}, f_{\mathrm{MC}}$, is represented by Eq. (33):

$f_{\mathrm{MC}}=K_{\mathrm{A}}^{\mathrm{MC}} R T S n_{\mathrm{m}}$,

where $n_{\mathrm{m}}$ is the mass concentration of the clay minerals [g $\left.\left(\mathrm{m}^{3} \text { of air }\right)^{-1}\right] ; R$ is the universal gas constant equal to $8.31 \mathrm{~Pa} \mathrm{~m}^{3} \mathrm{~mol}^{-1} \mathrm{~K}^{-1}$; and the $K_{\mathrm{A}}^{\mathrm{MC}}$ in m $\mathrm{m}^{-2} \mathrm{~Pa}^{-1} \mathrm{~mol}$ is defined by Eq. (34):

$K_{\mathrm{A}}^{\mathrm{MC}}=1.66 \times 10^{-24} K_{\mathrm{H}}^{\mathrm{MC}}$,

where the factor $1.66 \times 10^{-24}$ in mol is a result of the units in Eq. (34). Substituting Eq. (20) to Eq. (34) gives Eq. (35).

$K_{\mathrm{A}}^{\mathrm{MC}}=6.42 \times 10^{-15} \exp (4570 / T)$.

Let $X_{\mathrm{ad}}^{\mathrm{MC}}$ be the proportion of $\mathrm{CH}_{3} \mathrm{CCl}_{3}$ on clay minerals in all $\mathrm{CH}_{3} \mathrm{CCl}_{3}$ in the atmosphere. The $X_{\mathrm{ad}}^{\mathrm{MC}}$ is given as Eq. (36):

$X_{\mathrm{ad}}^{\mathrm{MC}}=f_{\mathrm{MC}} /\left(1+f_{\mathrm{MC}}\right)$.
Table 3. Estimated local lifetime ( $\left.\tau_{\text {dust }}^{\text {local }}\right)$ through the reaction on airborne dust. Blanks mean $>1000$ years

\begin{tabular}{|c|c|c|c|c|c|c|}
\hline$T(\mathrm{~K})$ & & & $\tau_{\text {dus }}^{\text {loc }}$ & (year) & & \\
\hline $10^{6} n_{\mathrm{m}}\left(\mathrm{g} \mathrm{m}^{-3}\right)$ & 1 & 10 & 50 & 100 & 200 & 500 \\
\hline 273 & & & & 600 & 300 & 100 \\
\hline 283 & & & 600 & 300 & 200 & 60 \\
\hline 298 & & & 300 & 100 & 70 & 30 \\
\hline 313 & & 600 & 100 & 60 & 30 & 10 \\
\hline 328 & & 300 & 60 & 30 & 20 & 6 \\
\hline
\end{tabular}

Substituting Eq. (33) to Eq. (36) gives Eq. (37):

$X_{\mathrm{ad}}^{\mathrm{MC}}=\frac{K_{\mathrm{A}}^{\mathrm{MC}} R T S n_{\mathrm{m}}}{1+K_{\mathrm{A}}^{\mathrm{MC}} R T S n_{\mathrm{m}}}$.

Assuming that the reaction rate is proportional to $a_{\mathrm{MC}}$ with a surface reaction rate constant of $k_{\text {clay }}\left(\mathrm{s}^{-1}\right)$ as described in the Sect. $2.4, \tau_{\text {dust }}^{\text {local }}-1$ can be estimated by Eq. (38):

$\tau_{\text {dust }}^{\text {local }-1}=3.15 \times 10^{7} \frac{k_{\text {clay }} K_{\mathrm{A}}^{\mathrm{MC}} R T S n_{\mathrm{m}}}{1+K_{\mathrm{A}}^{\mathrm{MC}} R T S n_{\mathrm{m}}}$,

where the factor $3.15 \times 10^{7}\left(\mathrm{y}^{-1} \mathrm{~s}\right)$ is a result of the units in Eq. (38).

From Eqs. (31), (35), and (38), the local lifetime of $\mathrm{CH}_{3} \mathrm{CCl}_{3}$ through the reaction on clay particles $\left(\tau_{\text {dust }}^{\text {local }}\right)$ can be calculated for different concentrations of clay minerals $\left(n_{\mathrm{m}}\right)$ in the atmosphere. The result is shown in Table 3. Blanks in Table 3 indicate $>1000$ years of lifetime.

Tegen and Fung (1994) modeled the atmospheric mineral dust cycle using a global three-dimensional model that included source regions and different size fractions of the soil components and their size distributions. The results indicated that the annual average concentration of clay-sized dust exceeds several $\mu \mathrm{g} \mathrm{m}^{-3}$ in the first dynamic layer (about 960 mbar) over and around the continents almost everywhere. Even if all of those clay-sized dust exhibit a similar activity for the decomposition of $\mathrm{CH}_{3} \mathrm{CCl}_{3}$ as illite (API no. $35^{*}$ ), $\tau_{\text {dust }}^{\text {local }}$ would be estimated to be $>1000$ years. This is much longer than the tropospheric lifetime of $\mathrm{CH}_{3} \mathrm{CCl}_{3}$ through the reaction with $\mathrm{OH}$ (6.0 years) (Prinn et al., 2001). We hence conclude that the reaction on airborne clays cannot serve as a significant tropospheric sink of $\mathrm{CH}_{3} \mathrm{CCl}_{3}$.

At the local scale, the reactions on airborne clay dusts will be significant only for high (e.g. hundreds of $\mu \mathrm{g} \mathrm{m}^{-3}$ ) concentrations of airborne clay minerals. The relative humidity dependence of the reaction shown in Sect. 3.3.2 indicates that the conditions required for the reaction may be present in arid and semi-arid regions. Here we consider the reaction on airborne dust over such dry regions. Model calculations indicate that the seasonal dust concentration in the planetary boundary layer ( 0 to $1 \mathrm{~km}$ altitude) exceeds $250 \mu \mathrm{g}$ 
$\mathrm{m}^{-3}$ over the western Sahara and the Sahel region, in parts of the Arabic Peninsula and Iran, and in the Asian source regions (Taklimakan and Gobi deserts) (Ginoux et al., 2001). The model calculation also shows that the volume fraction of clay-sized particles ( $<2 \mu \mathrm{m}$ of diameter in the coarse mode) in those dusts are approximately a half. Illite is estimated to be a dominant clay mineral in the Sahara Desert (Claquin et al., 1999). By sampling of airborne dusts and observation of their composition in the laboratory, illite minerals in dusts from deserts are detected with an IR spectrum (Blanco et al., 2002) or an XPS spectrum (Bruintjes et al., 2002). If half of the dust has an activity similar to that of illite (API no. $35^{*}$ ), the $\tau_{\text {dust }}^{\text {local }}$ value would be estimated to be a few hundred years at $283 \mathrm{~K}$ and about 60 years or less at $313 \mathrm{~K}$. The decomposition on airborne clays may hence contribute locally to the removal of $\mathrm{CH}_{3} \mathrm{CCl}_{3}$ in dust storms and plums, although it cannot be significant at the global scale.

\subsubsection{Estimated lifetime through decomposition on clays at the ground surface}

Higher concentrations of clay minerals are expected for reactions occurring close to the surface. In arid regions, the type of reaction studied here is expected to be significant because it proceeds easily under dry conditions. Temperatures in excess of $333 \mathrm{~K}$ at the surface of the Sahara Desert during the daytime should accelerate the reactions. Illite has been reported to be a dominant clay mineral in desert regions (Claquin et al., 1999), although the absolute concentrations are not known. Kaolinite, montmorillonite, and other clays have also been reported in desert regions (Potter and Rossman, 1977; Péwé et al., 1981; Verrecchia and Le Coustumer, 1996). The tropospheric lifetime of $\mathrm{CH}_{3} \mathrm{CCl}_{3}$ by the reaction at ground level ( $\left.\tau_{\text {ground }}^{\text {tropos }}\right)$ was estimated from the model reported by Alyea et al. (1978). We assumed a fairly dry desert surface. In this model, $\tau_{\text {ground }}^{\text {tropos }}$ in year is estimated as follows:

$\tau_{\text {ground }}^{\text {tropos }}=12.04 /\left(a N_{\mathrm{d}}\right)$,

where $N_{\mathrm{d}}$ is the area expressed as a multiple of the area of the model desert ( $1500 \mathrm{~km}$ wide and $3000 \mathrm{~km}$ long) and $a$ is the chemical removal efficiency of $\mathrm{CH}_{3} \mathrm{CCl}_{3}$ at the ground surface, which was determined experimentally as shown below (Alyea et al., 1978). The global desert areas are roughly equal to five model deserts $\left(N_{\mathrm{d}}=5\right)$. The $a$ value is taken to be the removal ratio of $\mathrm{CH}_{3} \mathrm{CCl}_{3}$ to the initial concentration experimentally determined for reaction periods of 3.5 days in a reactor $1 \mathrm{~m}$ high in which particles have been spread over the bottom. The parameter $a$ takes on values between 0 and 1. Let $n_{\mathrm{m}}^{\prime}$ be the average mass concentration of clay minerals in air below $1 \mathrm{~m}$ high on the ground surface. Let a soil density be $2.5 \mathrm{~g} \mathrm{~cm}^{-3}$. The $n_{\mathrm{m}}^{\prime}$ value in $\mathrm{g} \mathrm{m}^{-3}$ is represented by Eq. (40).

$n_{\mathrm{m}}^{\prime}=2.5 \times 10^{-2} d_{\mathrm{L}} C_{\mathrm{W}}$, where $d_{\mathrm{L}}$ in m means the top layer depth of the ground surface in which clays can contact with $\mathrm{CH}_{3} \mathrm{CCl}_{3}$ in the atmosphere; and $C_{\mathrm{W}}$ is the ratio of the weight of clays to that of all the sands at top layer of the ground surface. Assuming that the clays have an activity and surface area similar to that of illite (API no. $35^{*}$ ), the $a$ value in Eq. (39) was estimated by Eq. (41).

$a=1-\exp \left[\frac{-3.02 \times 10^{5} k_{\text {clay }} K_{\mathrm{A}}^{\mathrm{MC}} R T S n_{\mathrm{m}}^{\prime}}{1+K_{\mathrm{A}}^{\mathrm{MC}} R T S n_{\mathrm{m}}^{\prime}}\right]$,

where a factor $3.02 \times 10^{5}$ in s corresponds to reaction time of 3.5 days as mentioned above; $k_{\text {clay }}$ and $K_{\mathrm{A}}^{\mathrm{MC}}$ are calculated by Eqs. (31) and (35), respectively; $R$ is the universal gas constant equal to $8.31 \mathrm{~Pa} \mathrm{~m}^{3} \mathrm{~mol}^{-1} \mathrm{~K}^{-1} ; T$ is the temperature in $\mathrm{K}$; and $S$ in $\mathrm{m}^{2} \mathrm{~g}^{-1}$ is the BET specific surface area of illite (API no. $35^{*}$ ). The $\tau_{\text {ground }}^{\text {tropos }}$ value was estimated from the $a$ value thus obtained and Eq. (39) for different values of $N_{\mathrm{d}}$. The result was listed in Table 4. Blanks in Table 4 indicate $>1000$ years of lifetime.

In Table 4 , the case of $N_{\mathrm{d}}=5$ means that lifetime is evaluated for all desert regions in the world. The area of $N_{\mathrm{d}}=2$ is almost equal to that of the Sahara Desert. The case of $d_{\mathrm{L}}=2 \mu \mathrm{m}$ means that only clays exposed to the atmosphere can contact with $\mathrm{CH}_{3} \mathrm{CCl}_{3}$. The lengths of $d_{\mathrm{L}}=20 \mu \mathrm{m}$ and $2 \mathrm{~mm}$ correspond to maximum diameters defined for siltsized and small sand-sized particles, respectively. The calculation was performed for three cases (i)-(iii). In case (i), the value of $C_{\mathrm{w}}$ corresponds to a half of a clay-sized sand fraction $(<2 \mu \mathrm{m}$ in diameter of sands) reported from the field observations of the dry deposition of ozone onto the Lybian Desert in the Sahara Desert (Güsten et al., 1996). In case (iii), one-twentieth $\left(0.05 K_{\mathrm{A}}^{\mathrm{MC}}\right)$ of the value calculated by Eq. (35) was substituted for $K_{\mathrm{A}}^{\mathrm{MC}}$ in Eq. (41). The other parameters were set to be the same as those in the case (i). The case (iii) may correspond to the reaction under humidified conditions, for example, at about $20 \%$ relative humidity at $313 \mathrm{~K}$.

In estimation of the dry deposition rate for $\mathrm{O}_{3}$ to the desert sand, an aerodynamic resistance and a quasi-laminar boundary-layer resistance were reported to be insignificant compared with the bulk surface resistance (Güsten et al., 1996). The extent of deposition rates examined here for $\mathrm{CH}_{3} \mathrm{CCl}_{3}$ was $<10^{-6} \mathrm{~cm} \mathrm{~s}^{-1}$, which corresponded to several years of $\tau_{\text {ground }}^{\text {tropos }}$ or longer lifetime. This deposition rate was less than that reported for $\mathrm{O}_{3}$; hence, in calculating $a$, an aerodynamic resistance and a quasi-laminar boundary-layer resistance were not considered, and only bulk surface resistance was estimated.

Table 4 indicates that dry deposition originating from decomposition on clay minerals can be a significant removal process at ground level, involving $>10^{-4}$ by weight $\left(100 \mathrm{ppmw}\right.$ ) of clay minerals such as illite (API no. $35^{*}$ ) (Table 4). Hence, we conclude that the reactions in the top layer of the soil could serve as a significant tropospheric sink for $\mathrm{CH}_{3} \mathrm{CCl}_{3}$, if the relative humidity does not decrease 
Table 4. Estimated tropospheric lifetime $\left(\tau_{\text {ground }}^{\text {tropos }}\right)$ through the decomposition on the ground surface. Blanks mean $>1000$ years

\begin{tabular}{|c|c|c|c|c|c|c|c|c|c|c|}
\hline \multirow{3}{*}{$\begin{array}{c}T \\
(\mathrm{~K})\end{array}$} & \multicolumn{10}{|c|}{$\tau_{\text {ground }}^{\text {tropos }}$ (year) } \\
\hline & \multicolumn{2}{|l|}{$d_{L}(\mu \mathrm{m})$} & \multicolumn{2}{|c|}{2000} & \multicolumn{3}{|c|}{20} & \multicolumn{3}{|c|}{2} \\
\hline & $N_{d}$ & 5 & 2 & 0.5 & 5 & 2 & 0.5 & 5 & 2 & 0.5 \\
\hline \multicolumn{11}{|c|}{ case (i) $C_{\mathrm{w}}=0.4 \%$ by weight } \\
\hline 283 & & 2 & 6 & 20 & 40 & 100 & 400 & 400 & 1000 & \\
\hline 298 & & 2 & 6 & 20 & 20 & 50 & 200 & 200 & 400 & \\
\hline 313 & & 2 & 6 & 20 & 9 & 20 & 90 & 80 & 200 & 800 \\
\hline 328 & & 2 & 6 & 20 & 5 & 10 & 50 & 40 & 100 & 400 \\
\hline \multicolumn{11}{|c|}{ case (ii) $C_{\mathrm{w}}=100 \mathrm{ppmw}$} \\
\hline 283 & & 20 & 40 & 200 & & & & & & \\
\hline 298 & & 8 & 20 & 80 & 700 & & & & & \\
\hline 313 & & 5 & 10 & 50 & 300 & 800 & & & & \\
\hline 328 & & 3 & 8 & 30 & 200 & 400 & & & & \\
\hline \multicolumn{11}{|c|}{$\begin{array}{l}\text { case (iii) } C_{\mathrm{W}}=0.4 \% \text { by weight. In Eq. (20), the value of } 0.05 K_{\mathrm{A}}^{\mathrm{MC}} \text { is used } \\
\text { instead of that of } K_{\mathrm{A}}^{\mathrm{MC}} \text { calculated by Eq.(35). }\end{array}$} \\
\hline 283 & & 9 & 20 & 90 & 800 & & & & & \\
\hline 298 & & 5 & 10 & 50 & 300 & 800 & & & & \\
\hline 313 & & 3 & 8 & 30 & 200 & 400 & & & & \\
\hline 328 & & 3 & 6 & 30 & 80 & 200 & 800 & 800 & & \\
\hline
\end{tabular}

the reaction rate significantly. The difference in the reaction activity among illite materials (Table 1 ) is a remaining research subject. On the other hand, the reaction in semiarid regions that have larger amounts of clays than arid regions do could be significant, as could the transport of clay particles to arid and semiarid regions. The decomposition of $\mathrm{CH}_{3} \mathrm{CCl}_{3}$ over deserts might be found on the basis of the ALE/GAGE/AGAGE or NOAA/CMDL data. For example, at the station in Barbados, which is located in the North Atlantic Ocean, for the ALE/GAGE/AGAGE network, dust plumes passing over the Sahara Desert have been observed (Mahowald et al., 2002). The long-term continuous data on the atmospheric concentration of $\mathrm{CH}_{3} \mathrm{CCl}_{3}$ at the station might provide an opportunity to evaluate locally the contribution of heterogeneous decomposition over the Sahara Desert to $\mathrm{CH}_{3} \mathrm{CCl}_{3}$ lifetime.

\section{Conclusions}

By using the closed-circulation reactor, the reactions of $\mathrm{CH}_{3} \mathrm{CCl}_{3}$ on various types of the standard clay minerals were examined typically at $313 \mathrm{~K}$ and in dry air. The following conclusions were obtained.

- $\mathrm{CH}_{3} \mathrm{CCl}_{3}$ decomposes to $\mathrm{CH}_{2}=\mathrm{CCl}_{2}$ quantitatively on seven types (23 samples) of clay minerals via the elimination of $\mathrm{HCl}$ at temperatures appropriate to the lower troposphere. The decomposition occurs without photoillumination. Photoillumination does not accelerate the decomposition.
- The pseudo-first-order reaction rate constant is roughly proportional to the surface area of the clay sample. The surface area of clay sample such as porous montmorillonite should be estimated by the general (threeparameter) BET equation instead of the two-parameter BET equation.

- A parameter of the general BET equation $n$, the interlayer $\mathrm{Ca}^{2+}$ content, and the water content that can be removed easily from the clay minerals seem to be related to the activity of the clay materials.

- The decomposition of $\mathrm{CH}_{3} \mathrm{CCl}_{3}$ on clay minerals requires no special pretreatment of clay minerals, such as heating at high temperatures; hence, the reaction can be expected to occur in the environment.

- The reaction rate increases with increasing temperature and decreases with increasing relative humidity. This dependence indicates that the conditions required for the reaction may be present in hot and dry regions such as the Sahara Desert.

- The adsorption equilibrium coefficients and the surface reaction rate constants for an illite sample can be determined in the temperature range of $283-313 \mathrm{~K}$.

- The decomposition on clays in airborne dusts can be expected not to be a significant tropospheric sink of $\mathrm{CH}_{3} \mathrm{CCl}_{3}$. It may be significant locally in dust events and dust plumes. 
- The dry deposition due to the reaction on clays at the ground level in arid regions can be expected to serve as a tropospheric sink of $\mathrm{CH}_{3} \mathrm{CCl}_{3}$.

- Influence of a potential sink of $\mathrm{CH}_{3} \mathrm{CCl}_{3}$, decomposition on clays, on the inferred atmospheric $\mathrm{OH}$ concentration may be different between in the Northern Hemisphere and in the Southern Hemisphere, since deserts are distributed more widely in the Northern Hemisphere.

- The inhibiting effect of relative humidity on the decomposition of $\mathrm{CH}_{3} \mathrm{CCl}_{3}$ on clay minerals is an important research subject that should be further evaluated in the laboratory.

\section{References}

Alyea, F. N., Cunnold, D. M., and Prinn, R. G.: Meteorological constraints on tropospheric halocarbon and nitrous oxide destructions by siliceous land surfaces, Atmos. Environ., 12, 10091011, 1978.

Aochi, Y. O. and Farmer, W. J.: Spectroscopic evidence for the rate-limited accumulation of a persistent fraction of 1,2dichloroethane sorbed onto clay minerals, Environ. Sci. Technol., 29, 1760-1765, 1995.

Blanco, A., Castellano, A., Filippo, E., Manno, D., Perrone, M. R., and Serra, A.: Characterisation of African dust over south Italy, in Proceedings of 2002 Joint International Symposium on Atmospheric Chemistry within the Earth System, 49, Crete, 2002.

Bruintjies, R., Piketh, S. J., Mangoosh, A., Mandoos, A., Breed, D., Jensen, T., Salazar, V., and Ross, K. E.: Microphysical and radiative properties of clouds in the Middle East - United Arab Emirates, in Proceedings of 2002 Joint International Symposium on Atmospheric Chemistry within the Earth System, 91, Crete, 2002.

Butler, J. H., Elkins, J. W., Thompson, T. M., and Hall, B. D.: Oceanic consumption of $\mathrm{CH}_{3} \mathrm{CCl}_{3}$ :Implications for tropospheric OH, J. Geophys. Res., 96, 22 347-22 355, 1991.

Claquin, T., Schulz, M., and Balkanski, Y. J.: Modeling the mineralogy of atmospheric dust sources, J. Geophys. Res., 104, 22243 $22256,1999$.

Dentener, F., Carmichael, G. R., Zhang, Y., Lelieveld, J., and Crutzen, P. J.: Role of mineral aerosol as a reactive surface in the global troposphere, J. Geophys. Res., 101, 22 869-22 889, 1996.

DeMore, W. B., Sander, S. P., Golden, D. M., Hampson, R. F., Kurylo, M. J., Howard, C. J., Ravishankara, A. R., Kolb, C. E., abd Molina, M. J.: Chemical kinetics and photochemical data for use in stratospheric modeling, JPL Publ. 97-4, 1997.

Ginoux, P., Chin, M., Tegen, I., Prospero, J. M., Holben, B., Dubovik, O., and Lin S.-J.: Sources and distributions of dust aerosols simulated with the GOCART model, J. Geophys. Res., 106, 20 255-20 273, 2001.

Güsten, H., Heinrich, G., Mönnich, E., Sprung, D., Weppner, J., Ramadan, A. B., Ezz El-Din, M. R. M., Ahmed, D. M., and Hassan, G. K. Y.: On-line measurements of ozone surface fluxes: part II.
Surface-level ozone fluxes onto the Sahara desert, Atmos. Environ., 30, 911-918, 1996.

Hanisch, F. and Crowley, J. N.: Ozone decomposition on Saharan dust: an experimental investigation, Atmos. Chem. Phys., 3, 119-130, 2003.

Huang, J. and Prinn, R. G.: Critical evaluation of emissions for potential new OH titating gases, in Proceedings of 2002 Joint international Symposium on Atmospheric Chemistry within the Earth System, 22, Crete, 2002.

IPCC: Climate Change 2001: The Scientific Basis. Contribution of Working Group I to the Third Assessment Report of the Intergovernmental Panel on Climate Change (Houghton, J. T., Y. Ding, D. J. Griggs, M. Noguer, P. J. van der Linden, X. Dai, K. Maskell, and C. A. Johnson (Eds), Cambridge University Press, Cambridge, UK and New York, 881, 2001.

Jöckel, P., Brenninkmeijer, C. A. M., and Crutzen, P. J.: A discussion on the determination of atmospheric $\mathrm{OH}$ and its trends, Atmos. Chem. Phys., 3, 107-118, 2003.

Kerr, P. F. and Kurp, J. L.: Reference clay localities - united states, in American Petroleum Institute Project 49 Clay Minerals Standards, preliminary report No. 2, 1-106, Columbia University, New York, 1949.

Kerr, P. F., Hamilton, P. K., Pill, R. J., Wheeler, G. V., Lewis, D. R., Burkhardt, W., Reno, D., Taylor, G. L., La Habra Laboratory, Mielenz, R. C., King, M. E., and Schieltz, N. C.: Analytical data on reference clay materials, in American Petroleum Institute Project 49 Clay Minerals Standards, preliminary report No. 7, 38-58, Columbia University, New York, 1950.

Keyser, L. F., Moore, S. B., and Leu M.-T.: Surface reaction and pore diffusion in flow-tube reactors, J. Phys. Chem., 95, 54965502, 1991.

Khalaf, F. I., Al-Kadi, A., and Al-Saleh, S.: Mineralogical composition and potential sources of dust fallout deposits in Kuwait, northern arabian gulf, Sedimentary Geology, 42, 255-278, 1985.

Krol, M., van Leeuwen, P. J., and Lelieveld, J.: Global OH trend inferred from methylchloroform measurements, J. Geophys. Res., 103, 10 697-10711, 1998.

Krol, M. and Lelieveld, J.: Substantial emissions of 1,1,1trichloroethane over Europe in 2000 and 2001: Consequences for global OH inversions, in Proceedings of 2002 Joint International Symposium on Atmospheric Chemistry within the Earth System, 22-23, Crete, 2002.

Kutsuna, S., Takeuchi, K., and Ibusuki, T.: Laboratory study on heterogeneous degradation of methyl chloroform $\left(\mathrm{CH}_{3} \mathrm{CCl}_{3}\right)$ on aluminosilica clay minerals as its potential tropospheric sink, J. Geophys. Res., 105, 6611-6620, 2000a.

Kutsuna, S., Ibusuki, T., and Takeuchi, K.: Heterogeneous photoreaction of tetrachloroethene-air mixture on halloysite particles, Environ. Sci. Technol., 34, 2484-2489, 2000b.

Kutsuna, S., Chen, L., Nohara, K., Takeuchi, K., and Ibusuki, T.: Heterogeneous decomposition of $\mathrm{CHF}_{2} \mathrm{OCH}_{2} \mathrm{CF}_{3}$ and $\mathrm{CHF}_{2} \mathrm{OCH}_{2} \mathrm{C}_{2} \mathrm{~F}_{5}$ over various standard aluminosilica clay minerals in air at $313 \mathrm{~K}$, Environ. Sci. Technol., 36, 3118-3123, 2002.

Levenspiel, O.: Chemical reaction engineering, 3rd ed., 385-391, New York, John Wiley \& Sons, 1999.

Mahowald, N. M., Zender, C. S., Luo, C., Savoie, D., Torres, O., and del Corral, J.: Understanding the 30-year Barbados desert dust record, J. Geophys. Res., 107, 4561, 
doi:10.1029/2002JD002097, 2002.

Manning, M. R., Lowe, D. C., Moss, R., and Brailsford, G.: Trends and anomalies in southern hemisphere $\mathrm{OH}$ inferred from 12 years of ${ }^{14} \mathrm{CO}$ data, in Proceedings of 2002 Joint International Symposium on Atmospheric Chemistry within the Earth System, 22-23, Crete, 2002.

McCulloch, A. and Midgley, P. M.: The history of methyl chloroform emissions: 1951-2000, Atmos. Environ., 35, 5311-5319, 2001

Mochida, I., Take, J., Saito, Y., and Yoneda, Y.: Linear free-energy relationships in heterogeneous catalysis, VI, Catalytic elimination reaction of hydrogen chloride from chloroethanes on solid acids and bases, J. Org. Chem., 32, 3894-3898, 1968.

Montzka, S. A., Spivakovsky, C. M., Butler, J. H., Elkins, J. W., Lock, L. T., and Mondeel, D. J.: New observation constraints for atmospheric hydroxyl on global and hemispheric scales, Science, 288, 500-503, 2000

Mortland, M. M. and Raman, K. V.: Surface acidity of smectites in relation to hydration, exchangeable cation, and structure, Clays and Clay Minerals, 16, 393-398, 1968.

Murray, R. S. and Quirk, J. P.: Intrinsic failure and cracking of clay, Soil Sci. Soc. Am. J., 54, 1179-1184, 1990.

Ooki, A. and Uematsu, M.: Chemical interactions on the surface of the mineral dust particles with the acid gases during the ACEASIA intensive experiment, in Proceedings of 2002 Joint International Symposium on Atmospheric Chemistry within the Earth System, 73, Crete, 2002.

Péwé, T. L., Péwé, E. A., Péwé, R. H., Journaux, A., and Slatt, R. M.: Desert dust: characteristics and rates of deposition in central Arizona, in Desert Dust: origin, characteristics, and effect on man, Special Paper 186, T. L. Péwé (Ed), 169-190, Geol. Soc. of Am., Boulder, CO, 1981.

Potter, R. M. and Rossman, G. R.: Desert varnish: the importance of clay minerals, Science, 196, 1446-1448, 1977.

Prather, M. and Spivakovsky, C. M.: Tropospheric OH and the lifetimes of hydrochlorofluorocarbons, J. Geophys. Res., 95, 18 723-18 729, 1990.

Prinn, R. G., Rasmussen, R. A., Simmonds, P. G., Alyea, F. N., Cunnold, D. M., Lane, B. C., Cardelino, C. A., and Crawford, A. J.: The atmospheric lifetime experiment, 5, Results for $\mathrm{CH}_{3} \mathrm{CCl}_{3}$ based on 3 years of data, J. Geophys. Res., 88, 8415-8426, 1983.

Prinn, R. G., Weiss, R. F., Miller, B. R., Huang, J., Alyea, F. N., Cunnold, D. M., Frazer, P. J., Hartley, D. E., and Simmonds, P. G.: Atmospheric trends and lifetime of $\mathrm{CH}_{3} \mathrm{CCl}_{3}$ and global $\mathrm{OH}$ concentrations, Science, 269, 187-192, 1995.

Prinn, R. G., Zander, R. (Leader Authors), Cunnold, D. M., Elkins, J. W., Engel, A., Fraser, P. J., Gunson, M. R., Ko, M. K. W., Mahieu, E., Midgley, P. M., Russell III, J. M., Volk, C. M., Weiss, R. F.: Long-lived ozone-related compounds, Chapter 1 in Scientific assessment of ozone depletion: 1988, Global ozone research and monitoring project - report no. 44, Geneva, 1999.

Prinn, R. G., Huang, J., Weiss, R. F., Cunnold, D. M., Fraser, P. J., Simmonds, P. G., McCulloch, A., Harth, C., Salameh, P., O’Doherty, S., Wang, R. H. J., Porter, L., and Miller, B. R.: Evidence for substantial variations of atmospheric hydroxyl radicals in the past two decades, Science, 292, 1882-1888, 2001.

Ravishankara, A. R. and Albritton, D. L.: Methyl chloroform and the atmosphere, Science, 269, 183-184, 1995.
Rebbert, R. E. and Ausloos, P.: Stratospheric ozone depletion by halocarbons: Chemistry and transport, 68, Nat. Acad. of Sci., Washington, 1979.

Sing, K. S. W., Everett, D. H., Haul, R. A. W., Moscou, L., Pierotti, R. A., Rouquérol, J., and Siemieniewska, T.: Reporting physisorption data for gas/solid systems with special reference to the determination of surface area and porosity, Pure \& Appl. Chem., 57, 603-619, 1985.

Singer, A.: Illite in aridic soils, desert dusts and desert loess, Sedimentary Geology, 59, 251-259, 1988.

Solomon, D. H.: Clay minerals as electron acceptors and/or electron donors in organic reactions, Clays and Clay Minerals, 16, 31-39, 1968.

Spivakovsky, C. M., Logan, J. A., Montzka, S. A., Balkanski, Y. J., Foreman-Fowler, M., Jones, D. B. A., Horowitz, L. W., Fusco, A. C., Brenninkmeijer, C. A. M., Prather, M. J., Wofsy, S. C., and McElroy, M. B.: Three-dimensional climatological distribution of tropospheric $\mathrm{OH}$ : Update and evaluation, J. Geophys. Res., 105, 8931-8980, 2000.

Swoboda, A. R. and Kunze, G. W.: Reactivity of montmorillonite surfaces with weak organic bases, Soil Sci. Soc. Amer. Proc., 32, 806-811, 1968.

Tegen, I. and Fung, I.: Modeling of mineral dust in the atmosphere: sources, transport, and optical thickness, J. Geophys. Res., 99, 22 897-22 914, 1994.

Tie, X., Kao, C.-Y., Miroz, E. J., Cicerone, R. J., Alyea, F. N., and Cunnold, D. M.: Three-dimensional simulations of atmospheric methyl chloroform: effect of an ocean sink, J. Geophys. Res., 97, 20751-20 769, 1992.

Theng, B. K. G.: The chemistry of clay-organic reactions, Adam hilger, London, 1974.

Underwood, G. M., Song, C. H., Phadnis, M., Carmichael, G. R., and Grassian, V. H.: Heterogeneous reactions of $\mathrm{NO}_{2}$ and $\mathrm{HNO}_{3}$ on oxides and mineral dust: A combined laboratory and modeling study, J. Geophys. Res., 106, 18 055-18 066, 2001.

Verrecchia, E. P. and Le Coustumer, M.-N.: Occurrence and genesis of palygorskite and associated clay minerals in a Pleistocene calcrete complex, Sde Boqer, Negev Desert, Israel, Clay Miner., 31, 183-202, 1996.

Vogel, T. M., Criddle, C. S., and McCary, P. L.: Transformation of halogenated aliphatic compounds, Environ. Sci. Technol., 21, 722-736, 1987.

Weissman, M. and Benson, S. W.: $\mathrm{HCl}$ elimination from $\mathrm{C}_{2} \mathrm{HCl}_{5}$ : evidence for an abnormally high activation energy caused by beta-chlorine substitutes, Int. J. Chem. Kinet., 16, 941-945, 1984.

WMO: Scientific assessment of ozone depletion: 2002, global ozone research and monitoring project - report no. 47, 498 pp., Geneva, 2003.

Zielke, R. C., Pinnavaia, T. J., and Mortland, M. M.: Adsorption and reactions of selected organic molecules on clay mineral surfaces, in Reactions and movement of organic chemicals in soils, SSSA Special Publication Number 22, edited by B. L. Sawhney and K. Brown, Soil Science Society of America and American Society of Agronomy, Madison, Wisconsin, 81-97, 1989. 